\title{
Molecular and Functional Diversity of GABA-A Receptors in the Enteric Nervous System of the Mouse Colon
}

\author{
Mohsen Seifi, ${ }^{1}$ James F. Brown, ${ }^{1}$ Jeremy Mills, ${ }^{1}$ Pradeep Bhandari, ${ }^{1,2}$ Delia Belelli, ${ }^{3}$ Jeremy J. Lambert, ${ }^{3}$ Uwe Rudolph, ${ }^{4}$ \\ and Jerome D. Swinny ${ }^{1}$ \\ ${ }^{1}$ Institute for Biomedical and Biomolecular Sciences, School of Pharmacy and Biomedical Sciences, University of Portsmouth, P01 2DT, United Kingdom, \\ ${ }^{2}$ Department of Gastroenterology, Queen Alexandra Hospital, Portsmouth, P06 3LY, United Kingdom, ${ }^{3}$ Division of Neuroscience, Medical Research \\ Institute, Dundee University, Ninewells Hospital and Medical School, Dundee, DD1 9SY, United Kingdom, and ${ }^{4}$ Laboratory of Genetic Neuropharmacology, \\ McLean Hospital and Department of Psychiatry, Harvard Medical School, Belmont, Massachusetts 02478
}

The enteric nervous system (ENS) provides the intrinsic neural control of the gastrointestinal tract (GIT) and regulates virtually all GI functions. Altered neuronal activity within the ENS underlies various GI disorders with stress being a key contributing factor. Thus, elucidating the expression and function of the neurotransmitter systems, which determine neuronal excitability within the ENS, such as the GABA-GABA receptor $\left(\mathrm{GABA}_{\mathrm{A}} \mathrm{R}\right)$ system, could reveal novel therapeutic targets for such GI disorders. Molecular and functionally diverse $\mathrm{GABA}_{\mathrm{A}} \mathrm{Rs}_{\text {s }}$ modulate rapid GABAergic-mediated regulation of neuronal excitability throughout the nervous system. However, the cellular and subcellular $\mathrm{GABA}_{\mathrm{A}} \mathrm{R}$ subunit expression patterns within neurochemically defined cellular circuits of the mouse ENS, together with the functional contribution of $\mathrm{GABA}_{\mathrm{A}} \mathrm{R}$ subtypes to GI contractility remains to be determined. Immunohistochemical analyses revealed that immunoreactivity for the $\operatorname{GABA}_{\mathrm{A}} \mathrm{R}$ gamma $(\gamma) 2$ and alphas $(\alpha) 1,2,3$ subunits was located on somatodendritic surfaces of neurochemically distinct myenteric plexus neurons, while being on axonal compartments of submucosal plexus neurons. In contrast, immunoreactivity for the $\alpha 4-5$ subunits was only detected in myenteric plexus neurons. Furthermore, $\alpha-\gamma 2$ subunit immunoreactivity was located on non-neuronal interstitial cells of Cajal. In organ bath studies, $\mathrm{GABA}_{\mathrm{A}} \mathrm{R}$ subtype-specific ligands had contrasting effects on the force and frequency of spontaneous colonic longitudinal smooth muscle contractions. Finally, enhancement of $\gamma 2-\mathrm{GABA}_{\mathrm{A}} \mathrm{R}$ function with alprazolam reversed the stress-induced increase in the force of spontaneous colonic contractions. The study demonstrates the molecular and functional diversity of the $\mathrm{GABA}_{\mathrm{A}} \mathrm{R}$ system within the mouse colon providing a framework for developing $\mathrm{GABA}_{\mathrm{A}} \mathrm{R}$-based therapeutics in GI disorders.

Key words: alprazolam; immunohistochemistry; inflammatory bowel disease; irritable bowel syndrome; stress

\section{Introduction}

The enteric nervous system (ENS) is a large collection of neurons within the muscle wall of the gastrointestinal tract (GIT) which provides the intrinsic neural control of virtually all GI functions (Goyal and Hirano, 1996; Furness, 2006) with ENS neuropathies being thought to underlie a range of GI disorders (Di Nardo et al., 2008; Furness, 2008). Furthermore, exposure to psychosocial stress adversely affects GI function and is a risk factor for the development of GI disorders, such as inflammatory bowel disease

Received Jan. 31, 2014; revised June 19, 2014; accepted June 23, 2014.

Author contributions: M.S. and J.D.S. designed research; M.S. and J.D.S. performed research; D.B., J.J.L., and U.R. contributed unpublished reagents/analytic tools; M.S., J.F.B., J.M., P.B., D.B., J.J.L., U.R., and J.D.S. analyzed data; M.S. and J.D.S. wrote the paper.

This work was supported in part by a Research Development Fund award from the University of Portsmouth to J.D.S., MRC funding to D.B. and J.J.L. and NIH funding to U.R. We thank Professors Jean-Marc Fritschy and Werner Sieghart for the generous supply of antibodies against the various GABAAR subunits, and Stewart Gallacher, Richard Tite, Scott Rodaway, and Angela Scutt for expert technical assistance.

U.R. has provided professional services for Sunovion and for Concert Pharmaceuticals. The remaining authors declare no competing financial interests.

Correspondence should be addressed to Dr Jerome D. Swinny, School of Pharmacy and Biomedical Sciences, University of Portsmouth, St Michael's Building, White Swan Road, Portsmouth, P01 2DT, UK. E-mail: jerome.swinny@port.ac.uk.

DOI:10.1523/JNEUROSCI.0441-14.2014

Copyright $\odot 2014$ the authors $\quad 0270-6474 / 14 / 3410361-18 \$ 15.00 / 0$
(IBD) and irritable bowel syndrome (IBS; Mawdsley and Rampton, 2005; Larauche et al., 2009; Konturek et al., 2011). Importantly, altered levels of neuronal activity within the ENS are implicated in such GI disorders (Margolis and Gershon, 2009; Ohman and Simrén, 2010) with treatment aimed primarily at the alleviation of the symptoms (Di Nardo et al., 2008). Thus, elucidating the expression and function of the neurotransmitter systems which determine neuronal excitability within the ENS, such as the GABA-GABA $A_{A}$ receptor $\left(\mathrm{GABA}_{\mathrm{A}} \mathrm{R}\right)$ system (Krantis, 2000) could reveal novel therapeutic targets for such GI disorders.

$\mathrm{GABA}_{\mathrm{A}} \mathrm{Rs}$ are chloride permeable integral membrane ion channels composed of five interacting subunit proteins which mediate the effects of the neurotransmitter GABA (Farrant and Nusser, 2005). Although only five subunits are required to form a functional receptor, up to 19 molecularly distinct $\mathrm{GABA}_{\mathrm{A}} \mathrm{R}$ subunits have been identified (Olsen and Sieghart, 2009). $\mathrm{GABA}_{\mathrm{A}} \mathrm{R}$ biology has been pioneered in the CNS where diverse $G_{A B A} R$ subunit assembly combinations manifest in functionally (Belelli et al., 2009; Eyre et al., 2012) and pharmacologically (Rudolph and Knoflach, 2011) diverse receptor subtypes within distinct regions (Wisden et al., 1992; Fritschy and Mohler, 1995; Hörtnagl et al., 2013) of the CNS, emphasizing the importance of identifying which particular $\mathrm{GABA}_{\mathrm{A}} \mathrm{R}$ subunits are expressed within a 
particular neural system. Despite the recognized importance of $\mathrm{GABA}_{\mathrm{A}}$ Rs to neural function and clinical medicine, relatively less is known about $\mathrm{GABA}_{\mathrm{A}} \mathrm{R}$ expression and function within the peripheral nervous system and the ENS in particular.

$\mathrm{GABA}_{\mathrm{A}} \mathrm{R}$ subunit mRNA expression has been demonstrated in the rat small intestine (Zeiter et al., 1996; Poulter et al., 1999). However, the expression of particular $\mathrm{GABA}_{\mathrm{A}} \mathrm{R}$ subtypes at the cellular and subcellular level of neurochemically defined cells remains to be fully elucidated (Krantis et al., 1995). Furthermore, although pan- $\mathrm{GABA}_{\mathrm{A}} \mathrm{R}$ ligands have been used to demonstrate the effects of $\mathrm{GABA}_{\mathrm{A}} \mathrm{R}$ modulation on intestinal contractility (Tonini et al., 1987, 1989a; Roberts et al., 1993; Hebeiss and Kilbinger, 1999; Bayer et al., 2002, 2003), the functional contribution of specific $\mathrm{GABA}_{\mathrm{A}} \mathrm{R}$ subtypes to GI contractility is yet to be determined. Here, we provide high-resolution immunolocalization of the $\mathrm{GABA}_{\mathrm{A}} \mathrm{R} \alpha 1-5$ and $\gamma 2$ subunits on neurochemically defined ENS cells of the mouse colon and use $\mathrm{GABA}_{\mathrm{A}} \mathrm{R}$ subunitselective drugs to demonstrate that the pharmacological enhancement of the function of different $\mathrm{GABA}_{\mathrm{A}} \mathrm{R}$ subtypes has contrasting effects on the amplitude and frequency of spontaneous colonic longitudinal smooth muscle contractions in vitro. Finally, $\mathrm{GABA}_{\mathrm{A}} \mathrm{R}$ ligands reversed the stress-induced changes in colonic contractility suggesting a role for these agents in treating stress-induced GI disorders.

\section{Materials and Methods}

All procedures involving experimental animals were approved by the Ethics Committee of the University of Portsmouth and were performed by a personal license holder, in accordance with the Animals (Scientific Procedures) Act, 1986 (UK) and associated procedures.

Reverse transcription-PCR. Reverse transcription-PCR (RT-PCR) was used to detect which $\mathrm{GABA}_{\mathrm{A}} \mathrm{R}$ subunits are expressed in the mouse colon at the mRNA level with matched brain tissue used as the positive control. Adult male C57BL/6J mice (Charles River Laboratories; $(N=3)$ were killed by cervical dislocation and the segments of the colon and whole brain removed and snap frozen in liquid nitrogen. The frozen tissue was homogenized from which RNA was extracted using an RNeasy mini kit (Qiagen) according to the manufacturer's protocol. RNA was reverse transcribed into cDNA using SuperScript First-Strand Synthesis System for RT-PCR kit (Invitrogen). Equal amounts of cDNA (1-2 $\mu \mathrm{l}$ ) were then used for subsequent PCR using GoTaq green mastermix (Promega), PCR grade water and specific primers. Exon-exon spanning $\mathrm{GABA}_{\mathrm{A}} \mathrm{R}$ subunit specific PCR primers used in the study (Table 1) were previously published (Glassmeier et al., 1998; Gustincich et al., 1999; Tan et al., 2011). The RT-PCR transcript products for the $\mathrm{GABA}_{\mathrm{A}} \mathrm{R}$ subunits and the positive control $\beta$-actin from brain and colon tissue were run on a $2 \%$ agarose gel and the DNA was visualized under ultraviolet light using a SYBR green-based DNA stain.

Tissue preparation for immunohistochemistry. Adult male C57BL/6J (Charles River Laboratories) mice were anesthetized with isoflurane and pentobarbitone $(1.25 \mathrm{mg} / \mathrm{kg}$ bodyweight, i.p.). The animals were transcardially perfused using a fixative containing $1 \%$ paraformaldehyde and $15 \% \mathrm{v} / \mathrm{v}$ saturated picric acid in $0.1 \mathrm{~m}$ phosphate buffer, $\mathrm{pH} 7.4$, according to previously described protocols (Corteen et al., 2011). After perfusion, the brains and colons were removed and post-fixed in the same fixative overnight at $4^{\circ} \mathrm{C}$. The next day, tissue was washed in $0.1 \mathrm{M}$ phosphate buffer until it was clear of the fixative. Whole-mount preparations of the longitudinal muscle-myenteric plexus and circular musclesubmucosal plexus were obtained using a dissecting microscope and fine forceps, which were then stored in $0.1 \mathrm{M}$ phosphate buffer containing $0.05 \%$ sodium azide.

Immunohistochemistry. The native $\mathrm{GABA}_{\mathrm{A}} \mathrm{R}$ subunit immunoreactivity patterns within the ENS of the mouse colon were confirmed in at least four animals. Nonspecific binding of secondary antibodies was blocked by incubating the tissue with $20 \%$ normal horse serum for $2 \mathrm{~h}$ at room temperature. The tissue was incubated with cocktails of primary antibod-
Table 1. Table of RT-PCR primer sequences

\begin{tabular}{|c|c|c|c|}
\hline Gene & Primer sequence & $\begin{array}{l}\text { RT-PCR } \\
\text { product } \\
\text { length (bp) }\end{array}$ & Reference \\
\hline $\mathrm{GABA}_{\mathrm{A}} \mathrm{R} \alpha 1$ & $\begin{array}{l}\text { CCA AGT CTC CTT CTG GCT CAA CA } \\
\text { GGG AGG GAA TTT CTG GCA CTG AT }\end{array}$ & 111 & Tan et al., 2011 \\
\hline $\mathrm{GABA}_{\mathrm{A}} \mathrm{R} \alpha 2$ & $\begin{array}{l}\text { TTA CAG TCC AAG CCG AAT GTCCC } \\
\text { ACT TCT GAG GTT GTG TAA GCG TAG C }\end{array}$ & 103 & Tan et al., 2011 \\
\hline $\mathrm{GABA}_{\mathrm{A}} \mathrm{R} \alpha 3$ & $\begin{array}{l}\text { CAA GAA CCT GGG GAC TTT GTG AA } \\
\text { AGC CGA TCC AAG ATT CTA GTG AA }\end{array}$ & 119 & Tan et al., 2011 \\
\hline $\mathrm{GABA}_{\mathrm{A}} \mathrm{R} \alpha 4$ & $\begin{array}{l}\text { GAG ACT GGT GGA TTT TCC TAT GG } \\
\text { GGT CCA GGT GTA GAT CAT CTC ACT }\end{array}$ & 94 & Tan et al., 2011 \\
\hline $\mathrm{GABA}_{\mathrm{A}} \mathrm{R} \alpha 5$ & $\begin{array}{l}\text { CCC TCC TTG TCT TCT GTA TTT CC } \\
\text { TGA TGT TGT CAT TGG TCT CGT CT }\end{array}$ & 99 & Tan et al., 2011 \\
\hline $\mathrm{GABA}_{\mathrm{A}} \mathrm{R} \alpha 6$ & $\begin{array}{l}\text { TAC AAA GGA AGA TGG GCT ATT } \\
\text { ACG ATG GGC AAA GTC AGA GAG }\end{array}$ & 439 & Glassmeier et al., 1998 \\
\hline $\mathrm{GABA}_{\mathrm{A}} \mathrm{R} \beta 1$ & $\begin{array}{l}\text { GGG GCT TCT CTC TTT TCC CGT GA } \\
\text { GGT GTC TGG TAC CCA GAG TTG GT }\end{array}$ & 334 & Gustincich et al., 1999 \\
\hline $\mathrm{GABA}_{\mathrm{A}} \mathrm{R} \beta 2$ & $\begin{array}{l}\text { CAA CTC TGG GTG CCT GAC ACC TA } \\
\text { TCC TAA TGC AAC CCG TGC AGC AG }\end{array}$ & 495 & Gustincich et al., 1999 \\
\hline $\mathrm{GABA}_{\mathrm{A}} \mathrm{R} \beta 3$ & $\begin{array}{l}\text { GGT TTG CTG CGC TCA GAG CGT AA } \\
\text { TAC AGC ACT GTC CCA TCA GGG T }\end{array}$ & 390 & Gustincich et al., 1999 \\
\hline $\mathrm{GABA}_{\mathrm{A}} \mathrm{R} \gamma 1$ & $\begin{array}{l}\text { CAG TTT GCA TTT GTA GGG TTA CG } \\
\text { AGA CAC CCA GGA AAG AAC CAC TG }\end{array}$ & 165 & Gustincich et al., 1999 \\
\hline $\mathrm{GABA}_{\mathrm{A}} \mathrm{R} \gamma \mathrm{2}$ & $\begin{array}{l}\text { GGT GGA GTA TGG CAC CCT GCA TT } \\
\text { AGG CGG TAG GGA AGA AGA TCC GA }\end{array}$ & 322 & Gustincich et al., 1999 \\
\hline $\mathrm{GABA}_{\mathrm{A}} \mathrm{R} \gamma 3$ & $\begin{array}{l}\text { TGC TCG GTC CAG GAG GGT AGA } \\
\text { CTG ATC AGC TGC CTC AAC TGA ATT TTT }\end{array}$ & 592 & Gustincich et al., 1999 \\
\hline $\mathrm{GABA}_{\mathrm{A}} \mathrm{R} \delta$ & $\begin{array}{l}\text { GAC TAC GTG GGC TCC AAC CTG GA } \\
\text { ACT GTG GAG GTG ATG CGG ATG CT }\end{array}$ & 398 & Gustincich et al., 1999 \\
\hline $\mathrm{GABA}_{A} \mathrm{R} \varepsilon$ & $\begin{array}{l}\text { CAA TGC GAA GAA CAC TTG GAA GC } \\
\text { CTG GCA GCA GCA GCT TCT ATC TT }\end{array}$ & 225 & Gustincich et al., 1999 \\
\hline$\beta$-actin & $\begin{array}{l}\text { AGG CCA ACC GTG AAA AGA TG } \\
\text { ACC AGA GGC ATA CAG GGA CAA }\end{array}$ & 101 & Gustincich et al., 1999 \\
\hline
\end{tabular}

ies (Table 2), diluted in Tris buffer saline containing 0.3\% Triton X-100 (TBS-Tx) and $20 \%$ normal horse serum, overnight at $4^{\circ} \mathrm{C}$. After washing with TBS-Tx, the tissue was incubated in a mixture of appropriate secondary antibodies conjugated with either AlexaFluor 488 (Invitrogen), indocarbocyanine (Cy3; Jackson ImmunoResearch), and indodicarbocyanine (Cy5; Jackson ImmunoResearch) for $2 \mathrm{~h}$ at room temperature. The tissue was washed in TBS-Tx and mounted on glass slides in Mowiol mounting medium (Polysciences) and then coverslipped.

Antibody specificity. Although the specificity of all the antisera against the $\mathrm{GABA}_{\mathrm{A}} \mathrm{R}$ subunits used in this study have been reported upon extensively in other studies concerning the CNS (Table 2), the specificity of the signal obtained in the ENS in this study was confirmed using perfusionfixed, matched brain-colon tissue from $\mathrm{GABA}_{\mathrm{A}} \mathrm{R}$ subunit-specific genedeleted mice. Method specificity was also tested by omitting the primary antibodies in the incubation sequence. To confirm the absence of cross reactivity between IgGs in double- and triple-immunolabeling experiments, some sections were processed through the same immunohistochemical sequence, except that only an individual primary antibody was applied with the full complement of secondary antibodies.

Image acquisition. Sections were examined with a confocal laserscanning microscope (LSM710; Zeiss) using either a Plan Apochromatic $40 \times$ DIC oil objective (NA 1.3; pixel size $0.29 \mu \mathrm{m}$ ), a Plan Apochromatic $63 \times$ DIC oil objective (NA 1.4; pixel size $0.13 \mu \mathrm{m}$ ) or a Plan Apochromatic $100 \times$ DIC oil objective (NA 1.46; pixel size $0.08 \mu \mathrm{m}$ ). Z-stacks were used for routine evaluation of the labeling. All images presented represent a single optical section. These images were acquired using sequential acquisition of the different channels to avoid cross talk between fluorophores, with the pinholes adjusted to one airy unit. Images were processed with the software Zen 2008 Light Edition (Zeiss) and exported into Adobe Photoshop. Only brightness and contrast were adjusted for the whole frame, and no part of a frame was enhanced or modified in any way. 
Table 2. Details of primary antibodies used in the study

\begin{tabular}{|c|c|c|c|c|}
\hline Antibody & Host & Dilution & Source & Specificity/Reference \\
\hline ChAT & Goat & $1: 100$ & Millipore (AB144P) & Heinze et al., 2007; Härtig et al., 2007 \\
\hline c-Kit & Rat & $1: 250$ & eBioscience (14-1172) & Sato et al., 1996; Torihashi et al., 1995 \\
\hline CRF & Guinea-pig & 1:1000 & Peninsula Labs (T-5007) & Stanić et al., 2010; Armstrong et al., 2009 \\
\hline $\mathrm{GABA}_{\mathrm{A}} \mathrm{R} \alpha 1$ & Rabbit & $1: 5000$ & Synaptic systems (224203) & Wisłowska-Stanek et al., 2013; No signal in knockout mouse, this study \\
\hline $\mathrm{GABA}_{\mathrm{A}} \mathrm{R} \alpha 2$ & Rabbit & $1: 1000$ & $\begin{array}{l}\text { Werner Sieghart, antigen sequence } \alpha 2 \mathrm{~L} \text { amino acids } \\
\text { 322-357. R\# 28/16 Bleed \# 01/10/2002 }\end{array}$ & Pirker et al., 2000; No signal in knockout mouse, this study \\
\hline $\mathrm{GABA}_{\mathrm{A}} \mathrm{R} \alpha 3$ & Guinea-pig & $1: 3000$ & Jean-Marc Fritschy, Antigen sequence $\alpha 3 \mathrm{~N}$ amino acids-15. & Fritschy and Mohler, 1995; No signal in knockout mouse, this study \\
\hline $\mathrm{GABA}_{\mathrm{A}} \mathrm{R} \alpha 4$ & Rabbit & $1: 500$ & $\begin{array}{l}\text { Werner Sieghart, antigen sequence } \alpha 4 \text { amino acids } \\
379 \text { - 421. R\# 25/1 Bleed \# 19/03/2001 }\end{array}$ & Pirker et al., 2000; No signal in knockout mouse, this study \\
\hline $\mathrm{GABA}_{\mathrm{A}} \mathrm{R} \alpha 5$ & Rabbit & $1: 1000$ & $\begin{array}{l}\text { Werner Sieghart, antigen sequence } \alpha 5 \text { amino acids } \\
\text { 337-388. R\# 34/30 Bleed \# 17/12/2007 }\end{array}$ & Pirker et al., 2000; No signal in knockout mouse, this study \\
\hline $\mathrm{GABA}_{\mathrm{A}} \mathrm{R} \gamma 2$ & Rabbit & $1: 3000$ & Synaptic Systems (224003) & Fish et al., 2013 \\
\hline Kv2.1 & Mouse & $1: 1000$ & Neuromab (75-014) & $\begin{array}{l}\text { Western blot; band at 105-125 kDa; No signal in knockout mice; } \\
\text { Hermanstyne et al., } 2010\end{array}$ \\
\hline Map-2 & Chicken & $1: 500$ & Aves Labs (MAP0607) & Expression patterns as shown in previous studies \\
\hline Neuroligin2 & Rabbit & $1: 1000$ & Synaptic Systems (129203) & Chih et al., 2005; De Jaco et al., 2006 \\
\hline NOS & Sheep & $1: 1000$ & Millipore (AB1529) & Liu et al., 2008; Cauli et al., 2004 \\
\hline Serotonin transporter & Guinea-pig & $1: 250$ & Chemicon (AB1772) & Häring et al., 2007 Collin et al., 2000 \\
\hline Somatostatin & Rat & $1: 500$ & Millipore (MAB354) & Tanaka et al., 2011; Dimitrov and Usdin, 2010 \\
\hline VGAT & Guinea-pig & $1: 1000$ & Synaptic Systems (131004) & Schock et al., 2012; Geis et al., 2010 \\
\hline
\end{tabular}

Isometric tension recordings of the effects of $G A B A_{A} R$ subunit-specific ligands on colonic longitudinal muscle contractions from isolated mouse colon segments. The pharmacological activation of $\mathrm{GABA}_{\mathrm{A}}$ Rs within the colon was explored with a view to understanding their potential roles in one aspect of colon physiology, namely colonic smooth muscle contractility. Intestinal motility or peristalsis arises from the coordinated contraction and relaxation of circular and longitudinal smooth muscles (Smith and Robertson, 1998). The effect of the GABA-GABA $\mathrm{A}_{\mathrm{R}} \mathrm{system}$ on the contractility of intestinal circular smooth muscles has been widely explored (Tonini et al., 1989a,b; Bayer et al., 2002, 2003). Therefore, we focused on the effect of ENS GABA $\mathrm{A}_{\mathrm{A}} \mathrm{R}$ activation on longitudinal smooth muscle contraction by measuring the changes in the force and frequency of spontaneous contractions in vitro. The activity of the interstitial cells of Cajal (ICC) is thought to underlie such intestinal spontaneous contractions (Sanders and Ward, 2006). Six- to 8-week-old male mice were killed by cervical dislocation and the distal colon was removed and immediately placed in physiological solution containing the following (in $\mathrm{mm}$ ): $\mathrm{NaCl}$ 140, $\mathrm{NaHCO}_{3}$ 11.9, D+ glucose 5.6, $\mathrm{KCl} 2.7, \mathrm{MgCl}_{2} .6 \mathrm{H}_{2} \mathrm{O}$ 1.05, $\mathrm{NaH}_{2} \mathrm{PO}_{4} \cdot 2 \mathrm{H}_{2} \mathrm{O} 0.5, \mathrm{CaCl}_{2} 1.8$, warmed to $32^{\circ} \mathrm{C}$. The intraluminal contents were removed by gently flushing the colon with the physiological solution. Approximately 2-cm-long segments were mounted in a Harvard organ bath $(10 \mathrm{ml}$ chamber) filled with the physiological solution $\left(32^{\circ} \mathrm{C}\right)$ and bubbled with gas containing $95 \% \mathrm{O}_{2}$ and $5 \% \mathrm{CO}_{2}$. Contractile activity for each colon tissue strip was recorded using an isometric force transducer (range $0-25 \mathrm{~g}$ ) connected to a bridge amplifier, which was in turn connected to a dedicated data acquisition system (Power Lab 2.20 AD Instruments). The sampling frequency was set to $40 \mathrm{~Hz}$ and the sensitivity of recording was set to $500 \mathrm{mV}$. The apparatus was then calibrated using a $1 \mathrm{~g}$ weight to express the changes in the amplitude detected by the transducer into grams of force. The tissue was then placed under $1 \mathrm{~g}$ of resting tension and allowed to equilibrate for $30 \mathrm{~min}$. The AD instrument lab chart 7 program installed on a PC was used to monitor record and analyze the activity. After a stable baseline was established, the drugs were added to the bath and the tissue was allowed to reach maximum response. Ten minute epochs before and after the drug additions were used for quantification of the drug-induced changes in the force and frequency of colonic spontaneous contractions. One piece of tissue was used per animal. The frequency and amplitude of individual spontaneous contractions was manually counted before and after the drug and the average for that animal determined. A mean value for the individual averages was obtained for a particular drug. An $N$ value thus represents one animal and the data are presented as the mean \pm SD.

In a subset of experiments, we investigated the effects of alprazolam on the contractile responses evoked by transmural nerve stimulation $(10 \mathrm{~Hz}, 60 \mathrm{~V}$, and $0.2 \mathrm{~ms}$ duration; Bayer et al., 2003). The electric pulses were delivered for $10 \mathrm{~s}$ and a single contraction was observed as a result. The tissue was then washed several times with the physiological solution and allowed to stabilize for $15 \mathrm{~min}$. Alprazolam or TTX were then individually added to the bath for 10 min after which the electrical stimulation was repeated.

Acute restraint stress. To probe the possible involvement of $\mathrm{GABA}_{\mathrm{A}} \mathrm{Rs}$ in stress-induced alterations of GI contractile function or provide evidence of their therapeutic potential in associated disorders, we exposed mice to acute restraint stress (Buynitsky and Mostofsky, 2009) and compared the effects of the benzodiazepine alprazolam on the force and frequency of spontaneous colonic contractions. This model was used because it induces a robust local stress response within the GIT which engages a range of intestinal cellular elements, such as neurons, muscle, and immune cells (Taché and Perdue, 2004; Zheng et al., 2009). We focused on only one aspect of such a stress-response, the changes in longitudinal smooth muscle contractility. Animals were divided into stress and control experimental Groups 1 week before the start of the experiment to allow adaptation to the new cage environment before commencing the stress. To deliver restraint, mice were restrained for 60 min using a Broome rodent restrainer (Harvard Apparatus no. 52-0470). During the period of restraint, the mice were kept individually in standard housing cages containing a thin layer of corn cob. Control mice remained in their original cages and were left undisturbed in their home environment. Immediately after the period of restraint, the animals were killed by cervical dislocation and used for isometric tension recordings.

Drugs. The following drugs were used in this study: zolpidem (Tocris Biosciences), alprazolam (Sigma-Aldrich), TP003 (Tocris Biosciences), THIP hydrochloride (Tocris Biosciences), L-655, 708 (Tocris Biosciences). Apart from THIP hydrochloride, which was dissolved in distilled water, all other drugs were dissolved in DMSO. DMSO at the bath concentrations used had no effect on the amplitude or frequency of colonic spontaneous contractions in agreement with previous evidence (Bayer et al., 2002).

Statistical analysis. All data are presented as the arithmetic mean \pm SEM unless stated otherwise. Statistical comparisons were made using either Student's $t$ test (paired or unpaired where appropriate) or repeated-measures ANOVA (RMA; one-way), followed by the Tukey's post hoc test.

\section{Results}

\section{$\mathrm{GABA}_{\mathrm{A}} \mathrm{R}$ subunit mRNA expression in the mouse colon}

Currently, up to 19 different $\mathrm{GABA}_{\mathrm{A}} \mathrm{R}$ subunits are known to be expressed within the CNS (Sieghart, 2006). Previous studies on $\mathrm{GABA}_{\mathrm{A}} \mathrm{R}$ subunit expression in the PNS did not specifically re- 


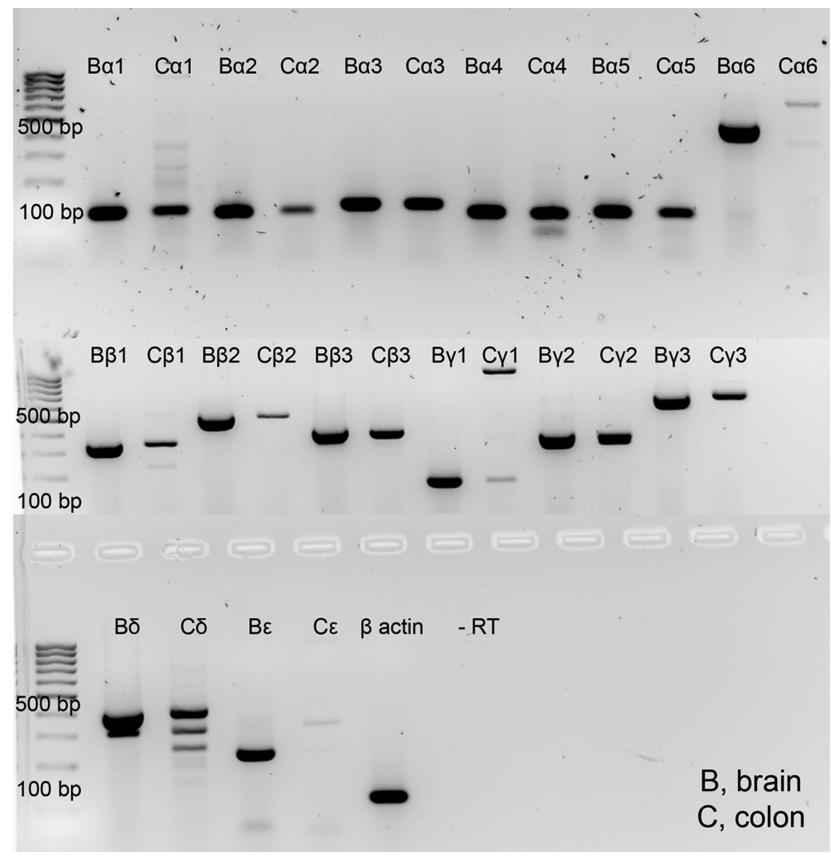

Figure 1. $G A B A_{A} R$ subunit mRNA expression in the mouse colon. Representative gel electrophoresis images of $m R N A$ transcripts for various $G A B A_{A} R$ subunits using RT-PCR and homogenates from whole mouse brain and colon. Corresponding amplicons of the same size to those obtained from brain samples were consistently detected for the $\mathrm{GABA}_{A} \mathrm{R} \alpha 1-5, \beta 1-3, \gamma 1-3$, and $\delta$ subunits but not the $\alpha 6$ and $\varepsilon$ subunits in colon samples ( $N=3$ animals). A negative control, no $R T$ reaction was performed with every experiment.

port expression patterns within the mouse colon (Akinci and Schofield, 1999; Poulter et al., 1999). RT-PCR performed on homogenates of mouse colon revealed mRNA expression for 14 of the $16 \mathrm{GABA}_{\mathrm{A}} \mathrm{R}$ subunits investigated (Fig. $1 ; N=3$ animals). No corresponding signal of the same size was detected for the $\mathrm{GABA}_{\mathrm{A}} \mathrm{R} \alpha 6$ and $\varepsilon$ subunits in the colon with mouse whole-brain homogenates serving as a positive control (Fig. 1).

\section{Immunolocalization of GABAergic synaptic marker proteins in the ENS of the mouse colon}

Immunoreactivity for putative presynaptic and postsynaptic GABAergic marker proteins was used to determine the distribution of GABAergic innervation across neuronal and nonneuronal cell-types in whole-mount preparations of the mouse colon. Microtubule associated protein 2 (MAP2), a pan-neuronal marker protein was used to visualize the somatodendritic domains of neurons located within the myenteric and submucosal plexuses. Immunoreactivity for the vesicular GABA transporter (VGAT), a protein which within the CNS is selectively expressed in GABAergic axon terminals was used to locate presumptive GABAergic input to different subcellular domains while immunoreactivity for neuroligin2 (NL2), a protein which in the CNS is selectively localized to GABAergic and glycinergic inhibitory synapses (Varoqueaux et al., 2004) was used to locate putative inhibitory postsynaptic domains with the caveat that ultrastructural studies are required to unequivocally demonstrate that, as is the case in the CNS, VGAT, and NL2 are located at inhibitory presynaptic and postsynaptic junctions. Immunoreactivity for the tyrosine-protein kinase Kit, c-Kit, was used to detect the nonneuronal ICCs (Maeda et al., 1992) which provide pacemaker activity in terms of colonic contractility (Garcia-Lopez et al., 2009). Immunoreactivity for VGAT was widely distributed among MAP2-immunoreactive somata and dendrites, as well as
c-Kit-immunoreactive profiles located within myenteric and submucosal plexuses (Fig. 2A). Immunoreactivity for NL2 presented as individual clusters which were concentrated on somatic and dendritic compartments of myenteric and submucosal plexus neurons and were closely apposed to VGAT-immunoreactive puncta (Fig. 2B). VGAT-immunoreactive clusters were also evident within colonic muscle layers and were distinctly associated with nitric oxide synthase (NOS)-immunoreactive axon terminals which appeared to innervate c-Kit immunoreactive ICCs (Fig. 2C). Thus, the putative sites of GABA release and predictive location of GABAergic receptors within the ENS of the mouse colon includes the neurons of the myenteric and submucosal plexuses as well as the non-neuronal ICCs.

Guided by the patterns of GABAergic innervation and the $\mathrm{GABA}_{\mathrm{A}} \mathrm{R}$ subunit mRNA expression patterns, immunohistochemistry and confocal microscopy was used to localize the expression of the $\mathrm{GABA}_{\mathrm{A}} \mathrm{R}$ gamma2 $(\gamma 2)$ and alphas $1-5(\alpha 1-5)$ subunits within neurochemically defined cell-types of the ENS of the mouse colon. $\mathrm{GABA}_{\mathrm{A}} \mathrm{R}$-subunit preferring ligands were then used to investigate the consequences of $\mathrm{GABA}_{\mathrm{A}} \mathrm{R}$ activation on spontaneous colonic longitudinal muscle contractions in vitro.

\section{Expression of the $\gamma 2$ subunit in the mouse colon and its role} in the regulation of longitudinal smooth muscle spontaneous contractions

Immunoreactivity for the $\gamma 2$ subunit was widely distributed across both neuronal and non-neuronal cell types of myenteric (Fig. 3A), and submucosal (Fig. 3B) plexuses, as well as the intramuscular layer (Fig. 3C). Within the myenteric plexus, immunoreactivity for the $\gamma 2$ subunit presented as distinct clusters almost exclusively located on the somatic and dendritic plasma membranes of NOS-, serotonin (5HT)-, corticotrophin releasing hormone (CRH)-, somatostatin (SOM)-, and choline acetyl transferase (Chat)-immunoreactive neurons (Fig. $3 A$ ). In contrast to the membrane-bound location of $\gamma 2$ subunit immunoreactivity in myenteric neurons, the location of the signal in NOS-immunopositive submucosal plexus neurons was predominantly cytoplasmic which might be suggestive of a presynaptic locus of expression (Fig. 3B). Thus, the targeting of $\gamma 2$ subunitcontaining $\mathrm{GABA}_{\mathrm{A}} \mathrm{Rs}\left(\gamma 2-\mathrm{GABA}_{\mathrm{A}} \mathrm{Rs}\right)$ to specific subcellular domains of ENS neurons is cell-type specific. Apart from expression in neurons, $\gamma 2$ subunit immunoreactivity was also evident on putative ICC-immunopositive for c-Kit located in proximity to the submucosal plexus (Fig. 3B) and muscle layers (Fig. 3C).

ICC are hypothesized to be the cellular links between ENS neurons and intestinal smooth muscle (Sanders and Ward, 2006; Huizinga et al., 2009) and are thus predominantly involved in GI contractility. Intestinal smooth muscle cells possess spontaneous rhythmic oscillations in their membrane potential, or slow waves which are the source of spontaneous contractions (Iino and Horiguchi, 2006). Myenteric and submucosal ICC are reportedly involved in the generation and propagation of these slow waves (Hirst and Ward, 2003; Sanders et al., 2004). In addition, the intramuscular ICC which are distributed among smooth muscle cells act as mediators of neurotransmission from the ENS to intestinal muscle cells (Ward et al., 2004). Importantly, it has been demonstrated that $\mathrm{GABA}$ and the $\mathrm{GABA}_{\mathrm{A}} \mathrm{R}$ agonist muscimol can modulate the amplitude of these spontaneous contractions in the rat colon (Bayer et al., 2002). The location of $\gamma 2$ subunit immunoreactivity at the interface between cell types which are implicated in regulating colon contractility suggests a possible involvement of $\gamma 2-\mathrm{GABA}_{\mathrm{A}} \mathrm{Rs}$ in such functions. Because the effects of $\mathrm{GABA}_{\mathrm{A}} \mathrm{R}$ ligands on the activity of GI circular smooth 


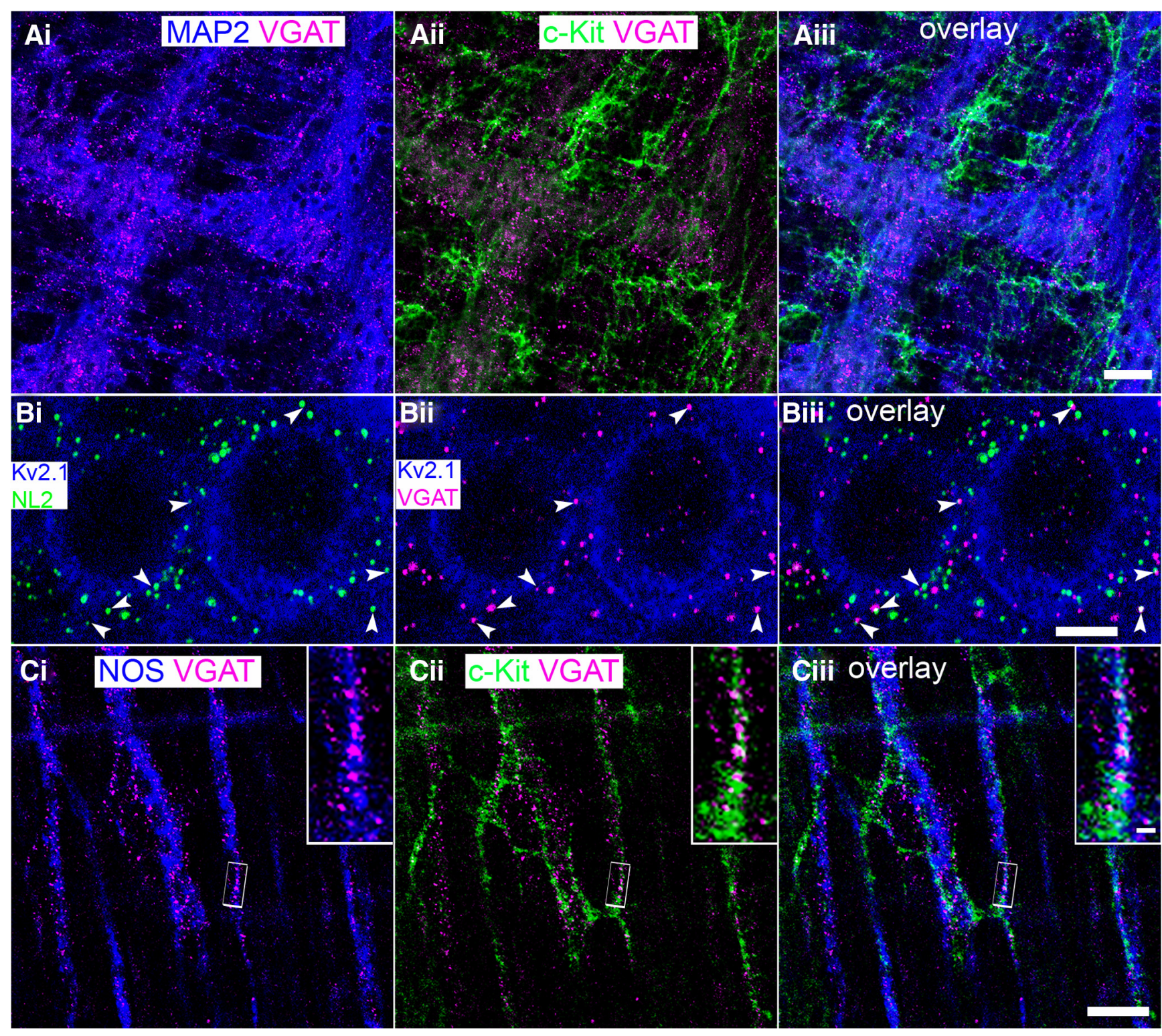

Figure 2. Immunolocalization of putative inhibitory synaptic marker proteins in the ENS of the mouse colon. Ai, Immunoreactivity for the somatodendritic MAP2 (blue) demonstrates the location of neurons within ganglia of the myenteric plexus. Immunoreactivity for the GABAergic presynaptic marker protein VGAT (red) shows the widespread GABAergic innervation of neurons throughout the ENS. Aii shows immunoreactivity for the ICC marker protein c-Kit (green) within the same field-of-view as Ai. Aiii is an overlay of $\boldsymbol{A} \boldsymbol{i}$ and $\boldsymbol{A i i}$, and demonstrates the association of VGAT immunoreactivity with neuronal and non-neuronal cells of the ENS within the mouse colon. Bi, Immunoreactivity for the Kv2.1 (blue) which delineates somato-dendritic plasma membranes, as well as immunoreactivity for NL2, a protein that in the CNS is located exclusively in inhibitory synapses (green). Bii, Immunoreactivity for VGAT within the same field-of-view as Bi. Biii is an overlay of Bi and Bii demonstrating the close association between putative presynaptic VGAT and postsynaptic NL2 immunoreactive clusters (arrowheads) and thus the likely locations of GABAergic synapses. Ci, NOS immunoreactive axon terminals (blue) which are also immunopositive for VGAT (red). Cii, VGAT-immunoreactive puncta are apposed to cellular profiles immunoreactive for c-Kit which are likely to be ICC. Ciii is an overlay of $C i$ and $C i i$ showing the close association between GABAergic axon terminals and the profiles of ICC. The insert is a magnified view of the boxed area. Scale bars: $A$, $30 \mu \mathrm{m} ; \boldsymbol{B}, 5 \mu \mathrm{m} ; \boldsymbol{C}, 20 \mu \mathrm{m} ;$ inset, $2 \mu \mathrm{m}$.

muscles have been reported on extensively (Tonini et al., 1989a,b; Bayer et al., 2002, 2003), we focused exclusively on their effects on longitudinal smooth muscle contractility. We therefore applied the benzodiazepine alprazolam to whole segments of mouse colon in a conformation that detects predominantly longitudinal smooth muscle activity and determined the changes in the force and frequency of spontaneous contractions; thus, our future reference in the manuscript to colonic contractility refers to longitudinal smooth muscle activity. Benzodiazepines as a class act as positive allosteric modulators at $\alpha 1 / 2 / 3 / 5-\beta-\gamma 2-\mathrm{GABA}_{\mathrm{A}} \mathrm{Rs}$ and therefore enhance the endogenous effects of GABA (Rudolph and Knoflach, 2011) with alprazolam in particular being a high- potency benzodiazepine widely prescribed for the treatment of generalized anxiety, panic attacks, and depression. Alprazolam at a bath concentration of $10 \mu \mathrm{M}$ induced a significant decrease in the basal tone of the tissue (from $-0.42 \pm 0.09 \mathrm{~g}$ to $-0.52 \pm 0.1 \mathrm{~g}$, $N=4$ animals; $p=0.003$, paired Student's $t$ test). Alprazolam also significantly decreased the force of spontaneous contractions (from $0.19 \pm 0.06 \mathrm{~g}$ to $0.08 \pm 0.04 \mathrm{~g}, N=4$ animals; $p=0.007$, paired Student's $t$ test) and increased their frequency (from $0.054 \pm 0.003 \mathrm{~Hz}$ to $0.071 \pm 0.009 \mathrm{~Hz}, p=0.0244$, paired Student's $t$ test). Thus, the activation of $\gamma 2-\mathrm{GABA}_{\mathrm{A}} \mathrm{Rs}$ (i.e., $\mathrm{GABA}_{\mathrm{A}}$ Rs containing, among others, the $\gamma 2$ subunit) has a direct effect on the amplitude and frequency of spontaneous colonic 

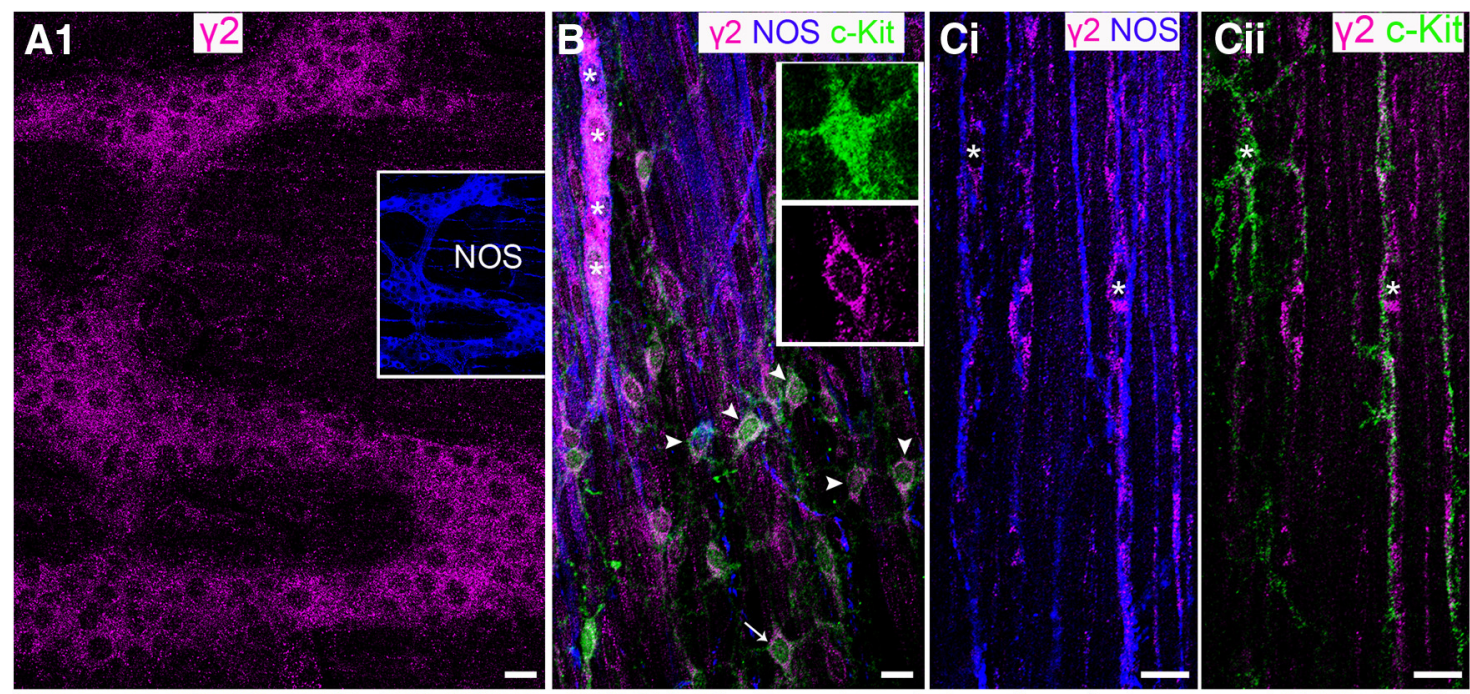
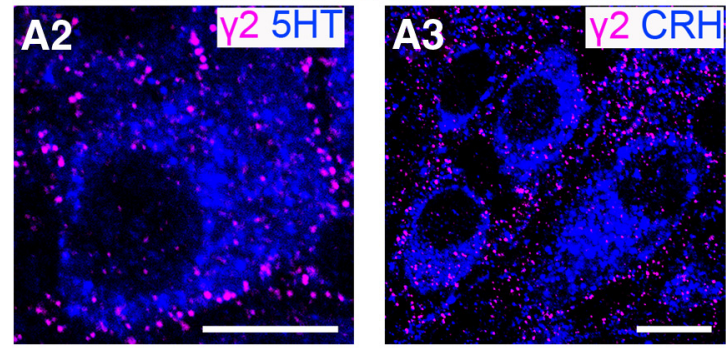

D1

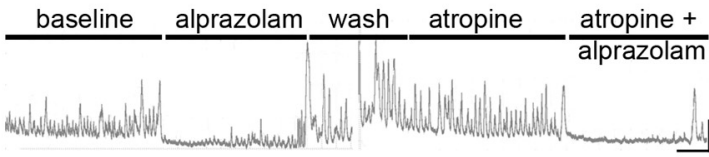

D2

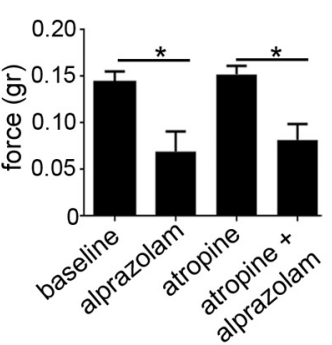

D3

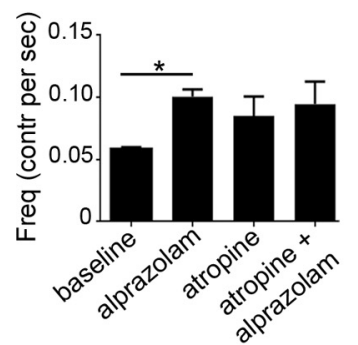

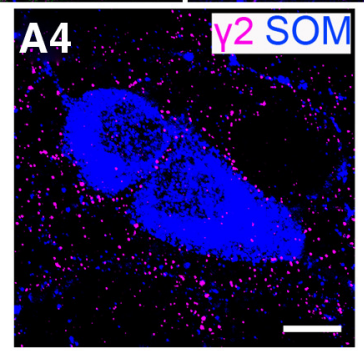

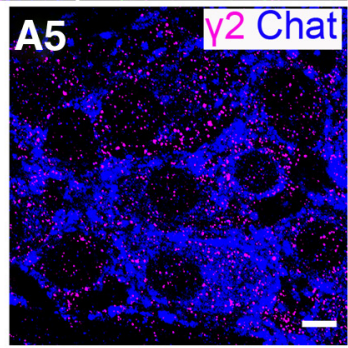

E1

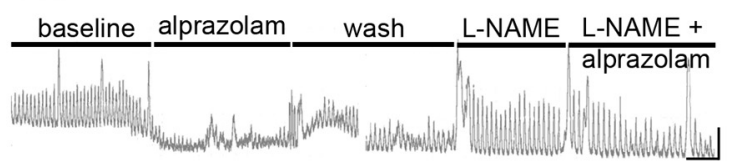

\section{E2}

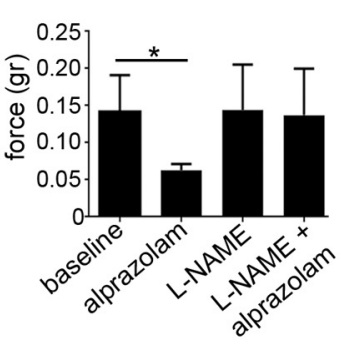

\section{E3}

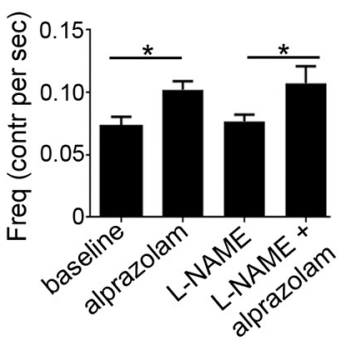

Figure 3. Immunolocalization of the $\mathrm{GABA}_{A} \mathrm{R} \gamma 2$ subunit in the ENS of the mouse colon and the pharmacological effect of activating $\gamma 2-\mathrm{GABA} \mathrm{A}_{\mathrm{R}}$ on spontaneous colonic longitudinal smooth muscle contractions. A1, Immunoreactivity for the $\gamma 2$ subunit is widely distributed on neurons of the myenteric plexus visualized by N0S immunoreactivity (inset). Immunoreactivity for the $\gamma 2$ subunit was located on somatodendritic surfaces of (A2) 5HT-, (A3) CRH-immunopositive, (A4) SOM-, nd (A5) Chat-immunopositive myenteric plexus neurons. $\boldsymbol{B}$, In contrast to the surface location of $\gamma 2$-subunit immunoreactivity on myenteric plexus neurons $(\boldsymbol{A})$, the signal in submucosal plexus neurons (asterisks) identified by NOS immunoreactivity, was located predominantly within the cytoplasm, as well as in c-Kit-immunopositive profiles (arrowheads). The inserts are magnified views of the cell identified by the arrow. $\boldsymbol{C}$, Within the muscle layer, $\gamma 2$ subunit immunoreactivity was closely associated with (Ci) NOS-immunopositive axon terminals and (Cii) C-Kit-immunopositive profiles (asterisks). D1, Representative trace demonstrating the effect of the benzodiazepine alprazolam $10 \mu \mathrm{m}$ on spontaneous contractions in a piece of isolated mouse colon in the absence and presence of the muscarinic cholinergic receptor antagonist atropine $1 \mu \mathrm{m}$. Quantification of the effects of alprazolam $10 \mu \mathrm{m}$, before and after the coapplication of atropine on (D2) the force and (D3) the frequency of spontaneous colonic contractions. E1, Representative trace demonstrating the effect of alprazolam $10 \mu \mathrm{m}$ on spontaneous contractions in a piece of isolated mouse colon in the absence and presence of the nitric oxide synthase inhibitor L-NAME $10 \mu \mathrm{m}$. Quantification of the effects of alprazolam $10 \mu \mathrm{M}$, before and after the coapplication of L-NAME on (E2) the force and (E3) the frequency of spontaneous colonic contractions. Error bars represent means and the lines represent the SD; $N=7$ animals, $^{*} p<0.05$, RMA with post hoc Tukey's test. Scale bars: $\boldsymbol{A 1}, 20 \mu \mathrm{m} ; \boldsymbol{A 2}-\mathbf{A 5}, 10 \mu \mathrm{m} ; \boldsymbol{B}, \boldsymbol{C}, 20 \mu \mathrm{m} ; \boldsymbol{D} 1, \boldsymbol{E 1}$, vertical $0.25 \mathrm{~g}$, horizontal 2 min.

longitudinal muscle contractions, as well as the basal tone of the colon.

The intricate expression patterns of the $\gamma 2$ subunit within the neurochemically diverse cell networks of the ENS raises the question whether the effects of alprazolam on colonic contractility occur directly or via secondary mediators. Two key neurochemical mediators of colonic contractility are acetylcholine, which within the intestine, signals primarily via cholinergic muscarinic receptors to cause intestinal contraction (Furness, 2006) and NO which acts via various intracellular and intercellular pathways to cause intestinal relaxation (Shah et al., 2004). To explore this further, we investigated the effects of alprazolam on the basal tone of the colon, as well as the force and frequency of spontaneous colonic contractions in the presence of either atropine a cholinergic muscarinic receptor antagonist or L-NAME, an inhibitor of the NO synthesizing enzyme nitric oxide synthase. Alprazolam 
significantly $\left(F_{(4,12)} 16.93, p<0.0001\right.$; RMA $)$ reduced the basal tone of the colon both alone $(p<0.05$, RMA) as well as in the presence of atropine ( $p<0.05$, RMA; $N=5$ animals; Fig. $3 D 1)$. Furthermore, alprazolam significantly $\left(F_{(4,12)} 52, p<0.0001\right.$; RMA) decreased the force of spontaneous colonic contractions on its own ( $p<0.05, \mathrm{RMA})$ as well as in the presence of atropine $(p<0.05$, RMA; $N=5$ animals; (Fig. 3D1,D2). In contrast, whereas alprazolam significantly $\left(F_{(4,12)} 4.22, p=0.02\right.$; RMA $)$ increased the frequency of colonic contractions on its own $(p<$ 0.05 , RMA), this effect was blocked in the presence of atropine ( $p>0.05, \mathrm{RMA} ; N=5$ animals; Fig. $3 D 3)$. Thus, the muscarinic cholinergic system is required for the effect of alprazolam on the frequency but not the force of colonic contractions.

Although alprazolam significantly $\left(F_{(6,18)} 11, p=0.0064\right.$; RMA) reduced the basal tone of the colon on its own $(p<0.05$, RMA; $N=7$ animals), this effect was abolished in the presence of L-NAME $(p>0.05$, RMA). In contrast to atropine, the alprazolam-induced $\left(F_{(6,18)} 5.78, p=0.0017\right.$; RMA $)$ decrease in the force of colonic contraction ( $p<0.05, \mathrm{RMA})$ was blocked in the presence of L-NAME ( $p>0.05$, RMA; $N=7$ animals; Fig. $3 E 1, E 2)$. However, the significant $\left(F_{(6,18)} 6.45, p=0.0001\right.$; RMA $)$ alprazolam-induced increase in the frequency of colonic contraction $(p<0.05, \mathrm{RMA})$ still persisted in the presence of $\mathrm{L}-\mathrm{NAME}$ $(p<0.05$, RMA; $N=7$ animals; Fig. 3E3). Thus, the nitric oxide system is engaged in mediating the effects of alprazolam on the basal tone as well as the force of colonic contractions.

Although the direct readout of the preparation used is smooth muscle contraction, it would be informative to confirm the involvement of the ENS in such effects. We therefore directly engaged neural elements by transmurally stimulating the colon segments using electrical field stimulation and measured the evoked contractile response (Fig. 4A). The application of TTX, a blocker of voltage-gated sodium channels, which in this preparation, are expressed by neuronal elements, significantly reduced the amplitude of the evoked response ( $p=0.003$, paired Student's $t$ test; Fig. $4 B$ ) confirming that neural activity underlies the evoked response. The application of alprazolam mimicked the effect of TTX by significantly reducing the amplitude of the evoked response ( $p=0.01$, paired Student's $t$ test; Fig. $4 B$ ). There was no significant difference between the evoked responses produced by TTX and alprazolam ( $p=0.07$, unpaired Student's $t$ test). This suggests that alprazolam directly engages the ENS and dampens overall neuronal excitability. Dedicated microelectrode studies are required to dissect the effects of $G A B A_{A} R$ subtype function at the single cell or cellular network, which manifest in regulating ENS out as a whole.

\section{Confirmation of the specificity of $\mathrm{GABA}_{\mathrm{A}} \mathrm{R}$ subunit}

immunoreactivity in brain and colon tissue from $\mathrm{GABA}_{\mathrm{A}} \mathrm{R} \alpha$ subunit specific gene-deleted $\left(\boldsymbol{\alpha}^{-/-}\right)$and WT mice

The specificity of the immunoreactivity patterns obtained by the antibodies against the $\alpha 1-5$ subunits was confirmed in tissue from the brain (Fig. 5) and colon (Fig. 6) of WT and $\alpha 1-5^{-1-}$ mice.

Expression of the $\alpha 1$ subunit in the mouse colon and its role in the regulation of longitudinal smooth muscle spontaneous contractions

Immunoreactivity for the $\alpha 1$ subunit was located on neurons of both the myenteric and submucosal plexuses (Fig. $7 A, B$ ). Clustered immunoreactivity for the $\alpha 1$ subunit was evident on MAP2-immunopositive myenteric plexus neurons closely mirroring the expression pattern of the $\gamma 2$ subunit signal (Fig. 7A1). Immunoreactivity for the $\alpha 1$ subunit presented as distinct clus-
A

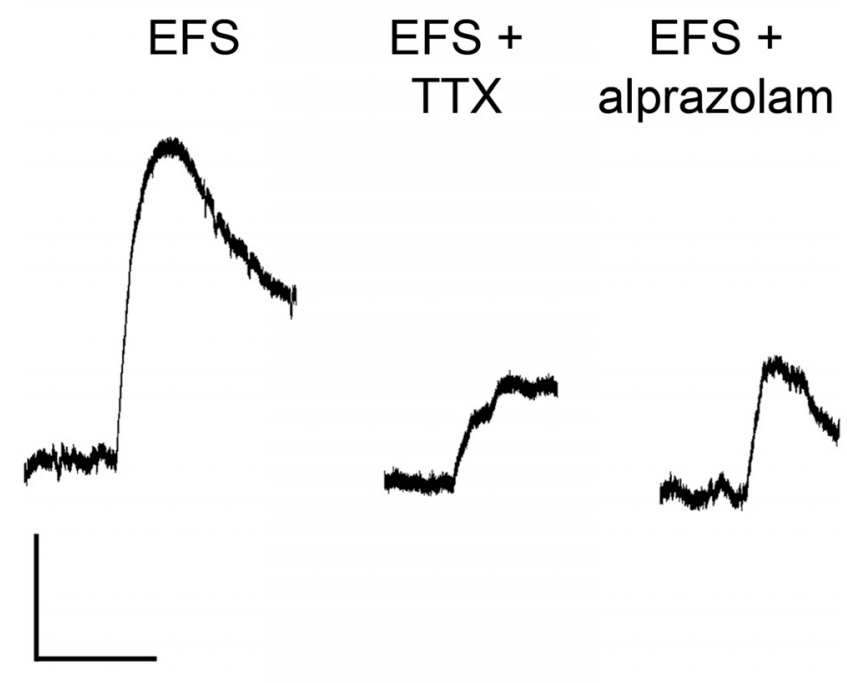

B

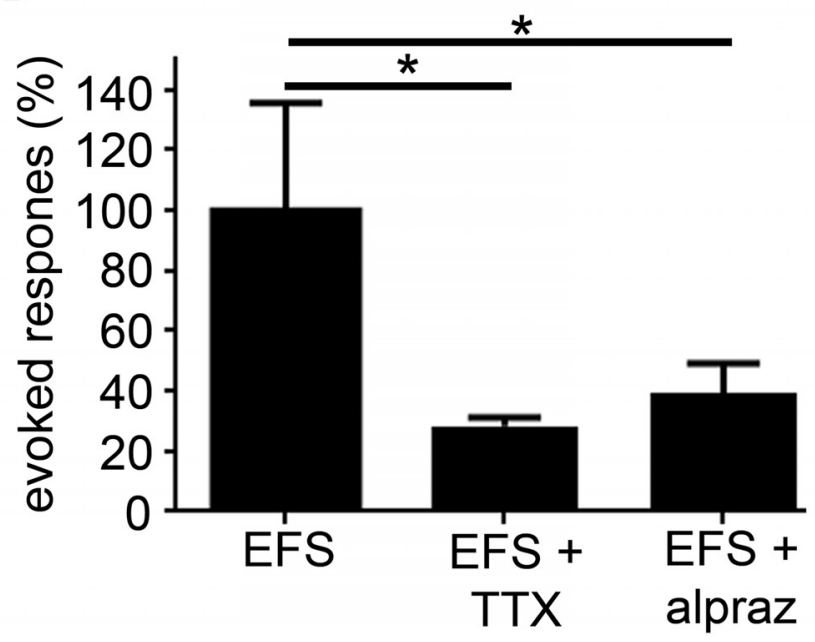

Figure 4. Effect of alprazolam on electrically evoked contractile responses of colon longitudinal smooth muscles. A shows representative records of the contractile responses of a colon segment following electrical field transmural stimulation either alone or in the presence of TTX, which blocks neural activity, or alprazolam. Note that both TTX and alprazolam attenuate the evoked response largely to the same degree. $\boldsymbol{B}$, Quantification of the effects of TTX and alprazolam on the evoked contractile responses. Error bars represent the mean percentage of the maximal response and the lines represent the $S D ; N=4$ animals, ${ }^{*} p<0.05$, paired Student's $t$ test. Scale bars: $A$, vertical $0.1 \mathrm{~g}$, horizontal $30 \mathrm{~s}$.

ters associated with VGAT immunoreactive clusters in close proximity to somatodendritic plasma membranes, which were delineated by the voltage-gated potassium channel 2.1 (Kv2.1), thus implying expression at inhibitory synaptic junctions (Fig. $7 A 2$ ). In addition, this clustered somatodendritic pattern of $\alpha 1$ subunit immunoreactivity was also evident on NOS, Chat-, 5HT-, and CRH-immunopositive myenteric neurons (Fig. 7A3A6). Furthermore, $\alpha 1$ subunit immunoreactivity was clustered on Chat-immunopositive varicosities in the muscle layer (Fig. 7A7). Immunoreactivity for the $\alpha 1$ subunit within submucosal plexus neurons also closely mirrored the pattern of the $\gamma 2$ subunit, appearing wholly cytoplasmic in NOS-immunoreactive neurons, with distinct $\alpha 1$ subunit immunoreactive clusters evident on NOS-immunoreactive axonal varicosities (Fig. $7 B$ ). This immunolocalization pattern suggests that $\alpha 1-\mathrm{GABA}_{\mathrm{A}} \mathrm{Rs}$ are lo- 

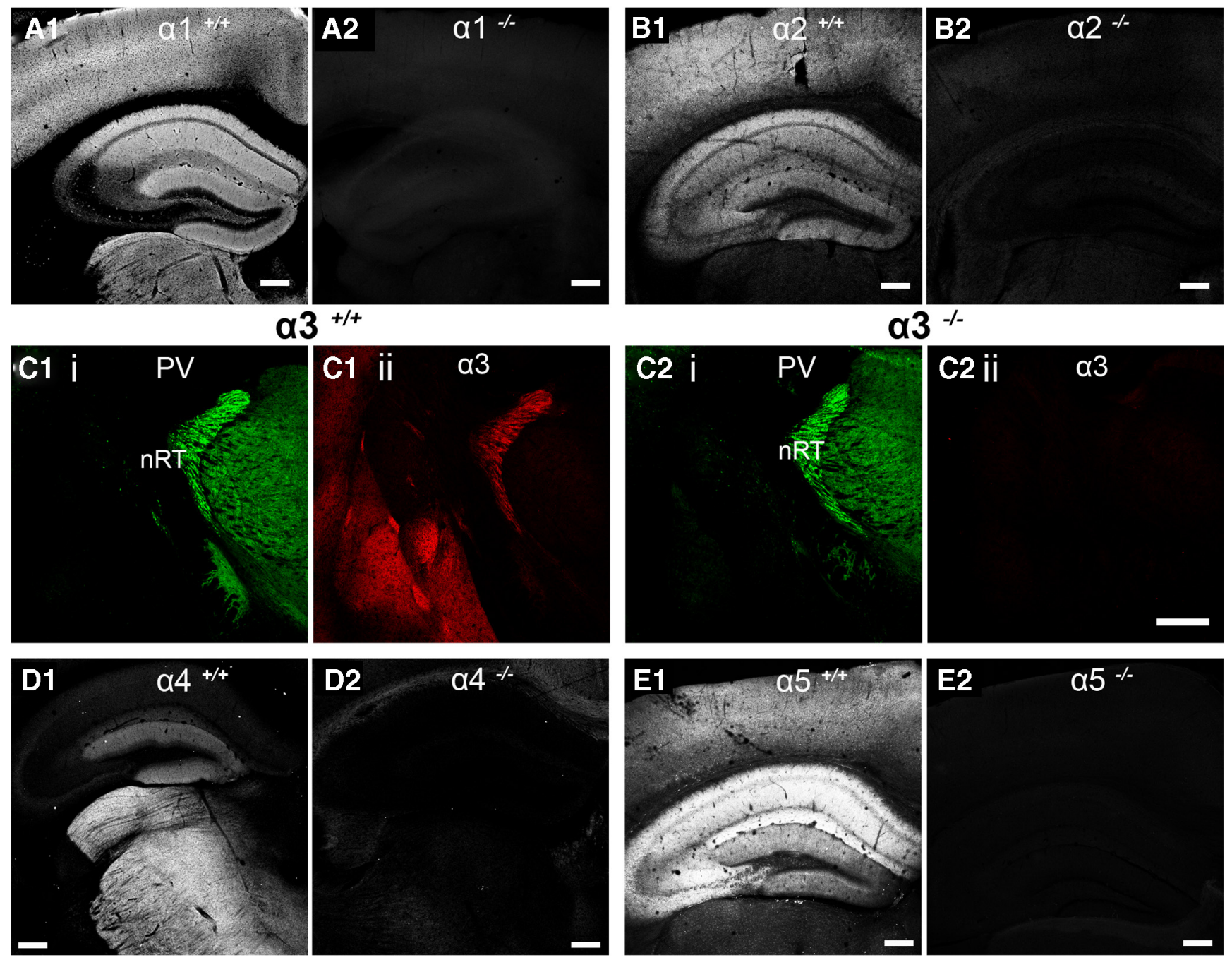

Figure 5. Confirmation of the specificity of the $G A B A_{A} R \alpha$ subunit immunoreactivity using tissue from the brains of wild-type $\left(W T ; \alpha^{+/+}\right)$and $G A B A_{A} R \alpha 1-5$ subunit-specific gene-deleted mice $\left(\alpha^{-l-}\right) \cdot A 1, B 1, D 1, E 1$, Characteristic immunoreactivity patterns for the $\alpha 1-2,4-5$ subunits in the hippocampus and neocortex of WT mouse brain respectively. C1, Characteristic enrichment of $\alpha 3$-subunit immunoreactivity within the reticular nucleus of the thalamus. $\mathbf{A 2}, \mathbf{B 2}, \mathbf{C 2}, \mathbf{D 2}$, E2, No specific signal was detectable in brain tissue from the appropriate $\alpha^{-1-}$ mice. Scale bars, $200 \mu \mathrm{m}$.

cated postsynaptically on myenteric plexus neurons and presynaptically on submucosal plexus neurons.

To investigate whether the activation of $\alpha 1-\mathrm{GABA}_{\mathrm{A}} \mathrm{Rs}$ influences colonic contraction, we applied the $\mathrm{GABA}_{\mathrm{A}} \mathrm{R}$ subunitselective imidazopyridine zolpidem to isolated mouse colon segments and measured the changes in the force and frequency of spontaneous contractions. Within the CNS, zolpidem at a concentration of $100 \mathrm{nM}$ is a selective positive allosteric modulator (PAM) of $\alpha 1-\gamma 2-\mathrm{GABA}_{\mathrm{A}} \mathrm{Rs}$, whereas a concentration of $1 \mu \mathrm{M}$ zolpidem has affinity not only for $\alpha 1-\gamma 2$, but additionally $\alpha 2 / 3$ $\gamma 2-\mathrm{GABA}_{\mathrm{A}} \mathrm{Rs}$ (Langer et al., 1990; Crestani et al., 2000; Peden et al., 2008). Zolpidem at a bath concentration of $100 \mathrm{~nm}$ significantly increased the force of spontaneous contractions $(p=$ 0.0246 , paired Student's $t$ test, $N=4$ animals; Fig. 7C1,C2). However, zolpidem at this concentration had no significant effect on the frequency of spontaneous contractions $(p=0.4228$, paired Student's $t$ test; $N=4$ animals; Fig. 7C1,C3).

Expression of the $\alpha 2,3$ subunits in the mouse colon and their role in the regulation of longitudinal smooth muscle spontaneous contractions

Immunoreactivity for the $\alpha 2$ subunit was more restricted compared with other subunits investigated and was localized prefer- entially on MAP2-immunopositive neurons of the myenteric plexus (Fig. 8A). In addition, within this region, $\alpha 2$ subunit immunoreactive clusters also decorated c-Kit-immunopositive profiles, the putative ICC (Fig. 8A). There was a noticeable gradient in the comparative levels of $\alpha 2$ subunit immunoreactivity in NOS-immunopositive neurons of the myenteric and submucosal plexuses with the latter exhibiting strikingly higher levels of signal, which in a similar manner to other $\mathrm{GABA}_{\mathrm{A}} \mathrm{R}$ subunits, was located cytoplasmically (Fig. $8 B, C$ ). Finally, somatostatin immunoreactive varicosities were closely apposed to $\alpha 2$ subunit immunoreactive clusters within the myenteric plexus (Fig. $8 D$ ) suggesting that GABA released from somatostatin-expressing neurons may signal via $\alpha 2-\mathrm{GABA}_{\mathrm{A}} \mathrm{Rs}$. Indeed, somatostatin is a neurochemical signature of GABAergic interneurons within the ENS (Furness, 2006). Immunoreactivity for the $\alpha 3$ subunit was restricted to the somatic and dendritic domains of somatostatin-immunopositive neurons (Fig. $8 E$ ) as well as neurons contacted by Chat-immunopositive varicosities (Fig. $8 F$ ) within the myenteric plexus. Furthermore $\alpha 3$ subunit immunoreactivity clusters were evident within the muscle layer and distinctly associated with NOS-immunopositive varicosities and c-Kit Immunopositive ICCs (Fig. 8G).

To investigate the potential functional roles of $\alpha 2 / 3-\mathrm{GABA}_{\mathrm{A}} \mathrm{Rs}$ in colonic contractility we applied zolpidem $1 \mu \mathrm{M}$ to isolated mouse 

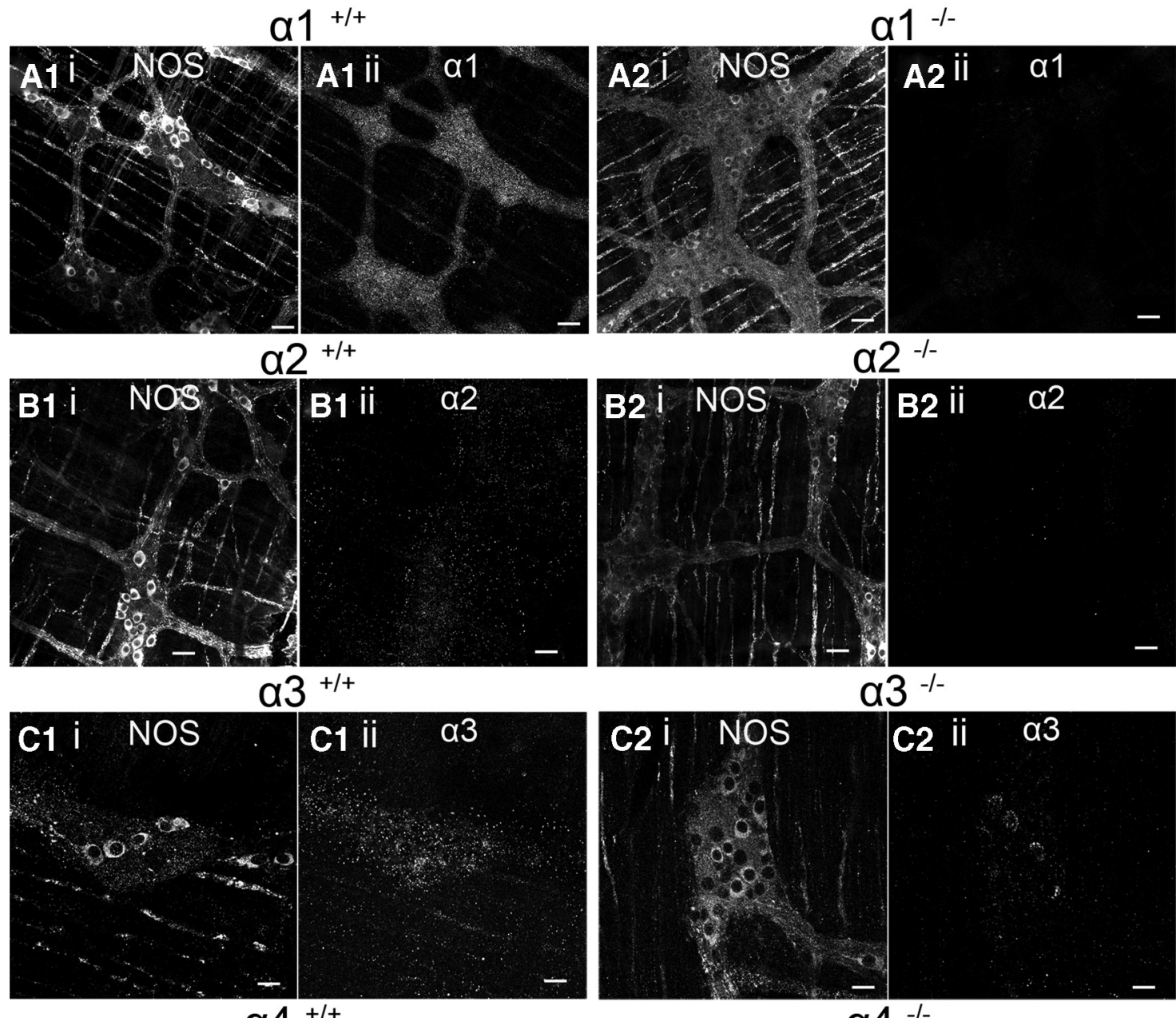

$\alpha 4$
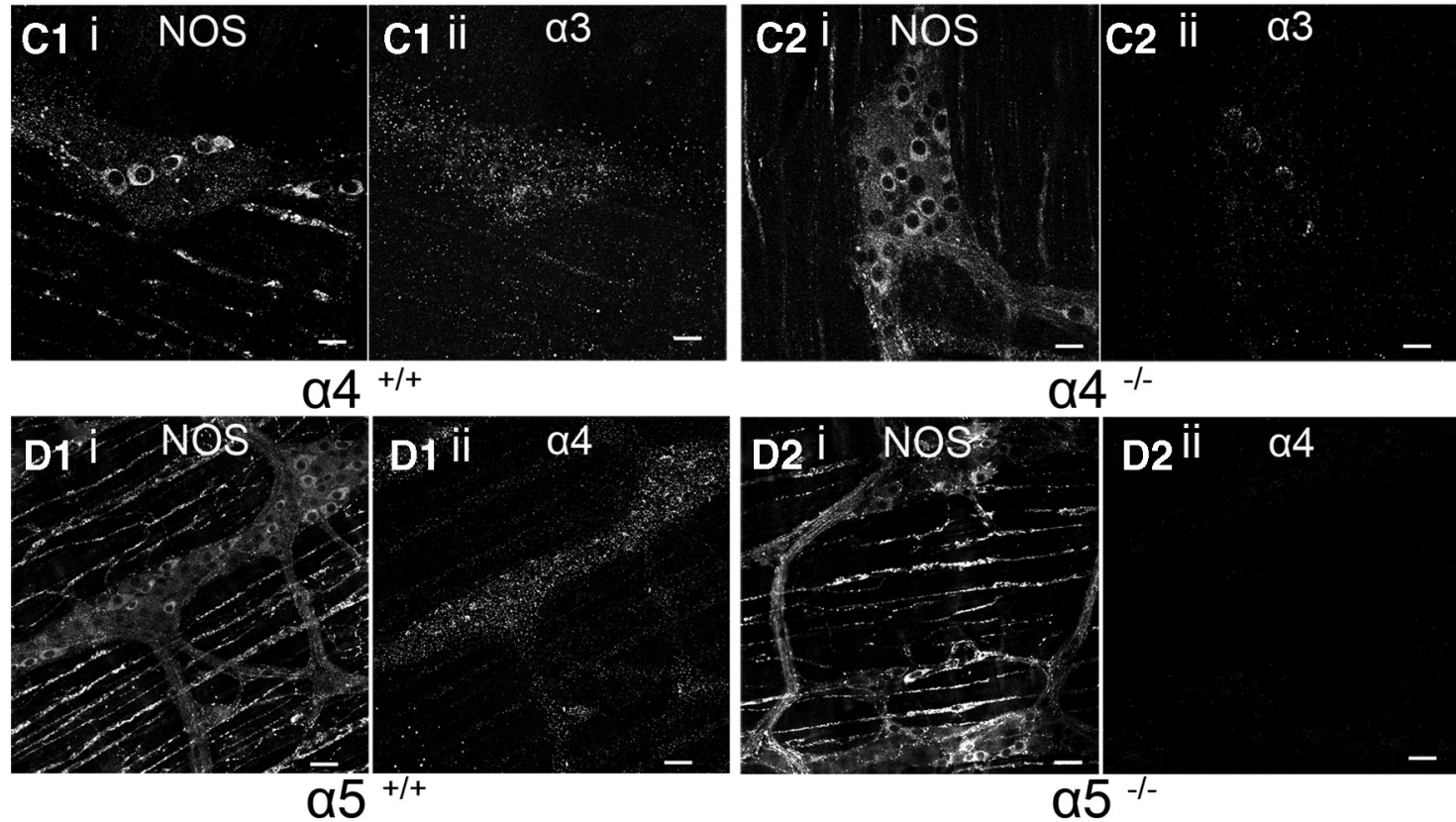

a4
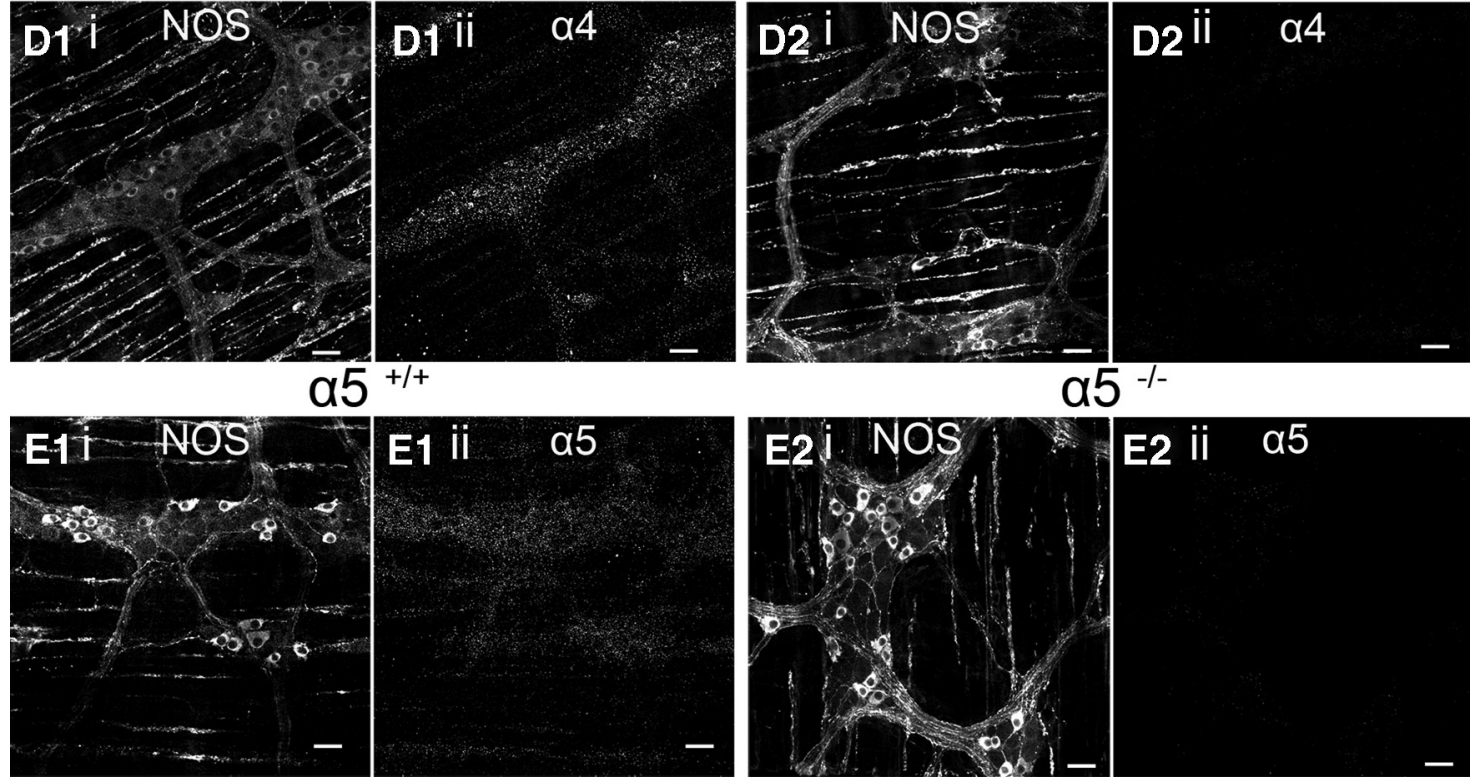

E2 î $a 5$

Figure 6. Confirmation of the specificity of the $G A B A_{A} R \alpha$ subunit immunoreactivity using tissue from the colons of wild-type $\left(W T ; \alpha^{+/+}\right)$and $G A B A_{A} R \alpha 1-5$ subunit-specific gene-deleted mice $\left(\alpha^{-1-}\right)$. A1-E1, Images of whole-mount preparations of the ENS of WT mouse colon demonstrating myenteric plexus neurons identified by (A1i-E1i) NOS immunoreactivity. (A1ii-E1ii) in the corresponding fields of view, $\alpha 1-5$-subunit immunoreactivity respectively is strongly associated with myenteric plexus neurons. (A2i-E2i) are images of whole-mount preparations of the ENS of $\alpha 1-5^{-l-}$ colon respectively demonstrating myenteric plexus neurons identified by NOS immunoreactivity. A2ii-E2iii in the corresponding fields-of-view, no specific $\alpha 1-5$ subunit signal respectively was detectable. Scale bars: $A, B, 40 \mu \mathrm{m}$. 

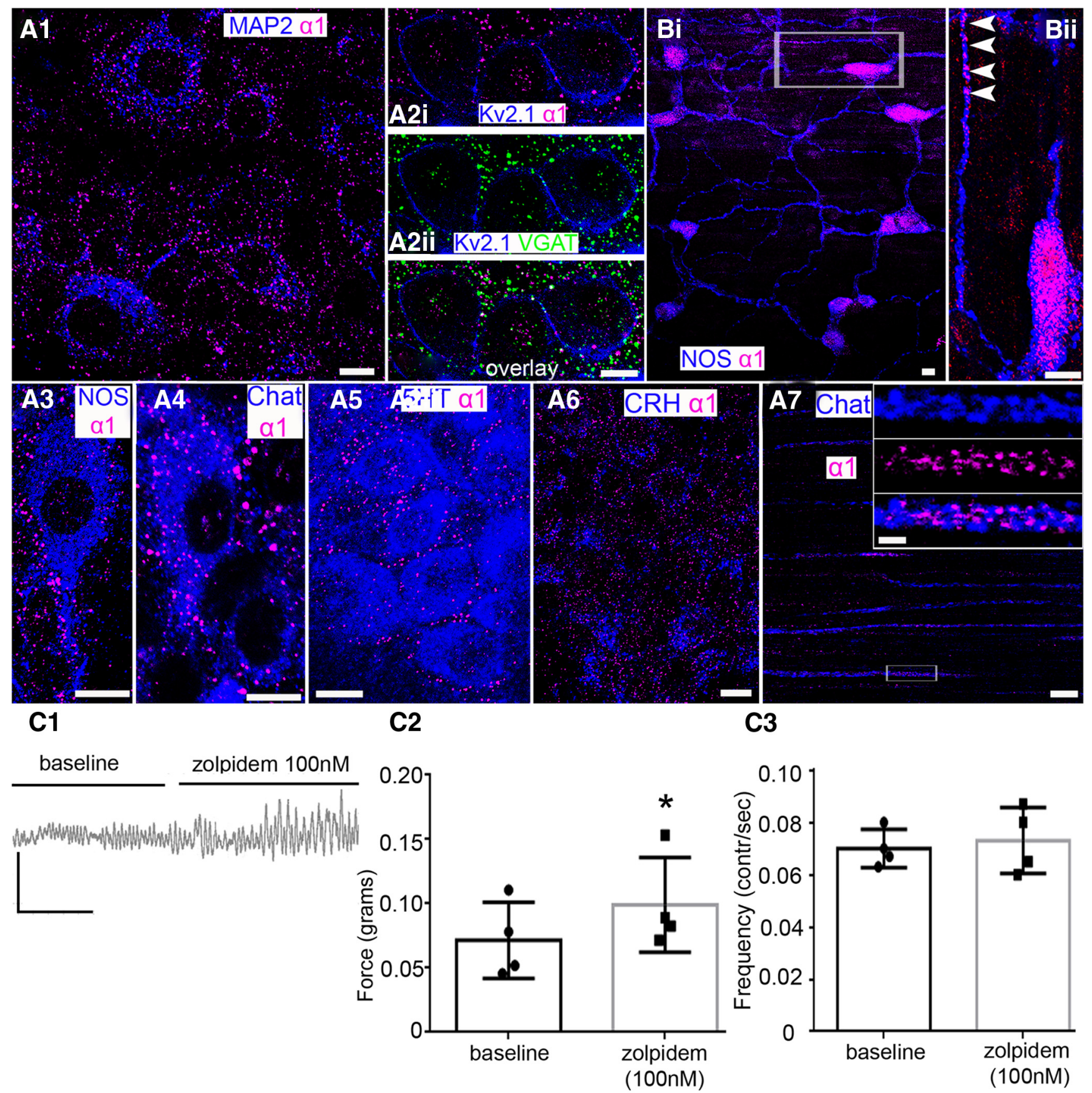

Figure 7. Immunolocalization of the $G A B A_{A} R \alpha 1$ subunit in the ENS of the mouse colon and the pharmacological effect of activating $\alpha 1-G A B A_{A} R s$ on spontaneous colonic longitudinal smooth muscle contractions. A1, Clustered $\alpha 1$ subunit immunoreactivity (red) was widely distributed on the somatodendritic surfaces of MAP2-immunopositive myenteric plexus neurons (blue). A2i, $\alpha 1$-Subunit immunoreactivity (red) on plasma-membrane surfaces, identified by Kv2.1 immunoreactivity (blue) is closely apposed to (A2ii, Aiii) VGAT immunoreactive puncta (green) and thus likely GABAergic synaptic junctions. Immunoreactivity for the $\alpha 1$ subunit was located on somato-dendritic surfaces of (A3) NOS-, (A4) Chat-, (A5) 5HT-, and (A6) CRH-immunopositive myenteric plexus neurons as well as (A7) Chat-immunopositive axon terminals in the muscle layer. $\boldsymbol{B}$, Shows that $\alpha 1$ subunit immunoreactivity within neurons of the submucosal plexus was located on cytoplasmic and axonal compartments. (Bii) is a magnified view of the boxed area in (Bi). C1, Representative trace demonstrating the effects of the application of zolpidem at a concentration of 100 $\mathrm{nm}\left(\alpha 1-\mathrm{GABA}_{\mathrm{A}} \mathrm{R}\right.$ selective agonist) on the spontaneous contractions in a piece of isolated colon. Quantification of the effects of zolpidem $100 \mathrm{~nm}$ on (C2) the force and (C3) the frequency of spontaneous colonic contractions. Boxes represent means, the lines represent the SD, and the small squares represent the individual data points; $N=4$ animals, ${ }^{*} p<0.05$, paired $S t u d e n t$ 's $t$ test. Scale bars: $\boldsymbol{A}, 10 \mu \mathrm{m} ; \boldsymbol{A} \mathbf{7}$ inset, $2 \mu \mathrm{m} ; \boldsymbol{B}, 10 \mu \mathrm{m} ; \boldsymbol{C}$, vertical $0.5 \mathrm{~g}$, horizontal $5 \mathrm{~min}$.

colon and measured the changes in the force and frequency of spontaneous contractions. At this concentration, zolpidem is expected to enhance the function of $\alpha 2 / 3-\gamma 2$ in addition to $\alpha 1-\gamma 2-\mathrm{GABA}_{\mathrm{A}} \mathrm{Rs}$ (Peden et al., 2008). Zolpidem at a bath concentration of $1 \mu \mathrm{M}$ significantly decreased the force of spontaneous contractions $(p=$ 0.0133 , paired Student's $t$ test; $N=4$ animals; Fig. $8 H 1$ ) and in- creased their frequency ( $p=0.0237$, paired Student's $t$ test; $N=4$ animals; Fig. 8H2). To dissect the potential contrasting roles of $\alpha 2$ and $\alpha 3-\mathrm{GABA}_{\mathrm{A}} \mathrm{Rs}$ on the force and frequency of spontaneous colonic contractions, we used the $\mathrm{GABA}_{\mathrm{A}} \mathrm{R}$ ligand TP003, which in recombinant systems is a selective PAM of $\alpha 3-\gamma 2-\mathrm{GABA}_{\mathrm{A}} \mathrm{Rs}$ (Dias et al., 2005). A caveat is that TP003 may lack this $\alpha 3$ subunit selectively 

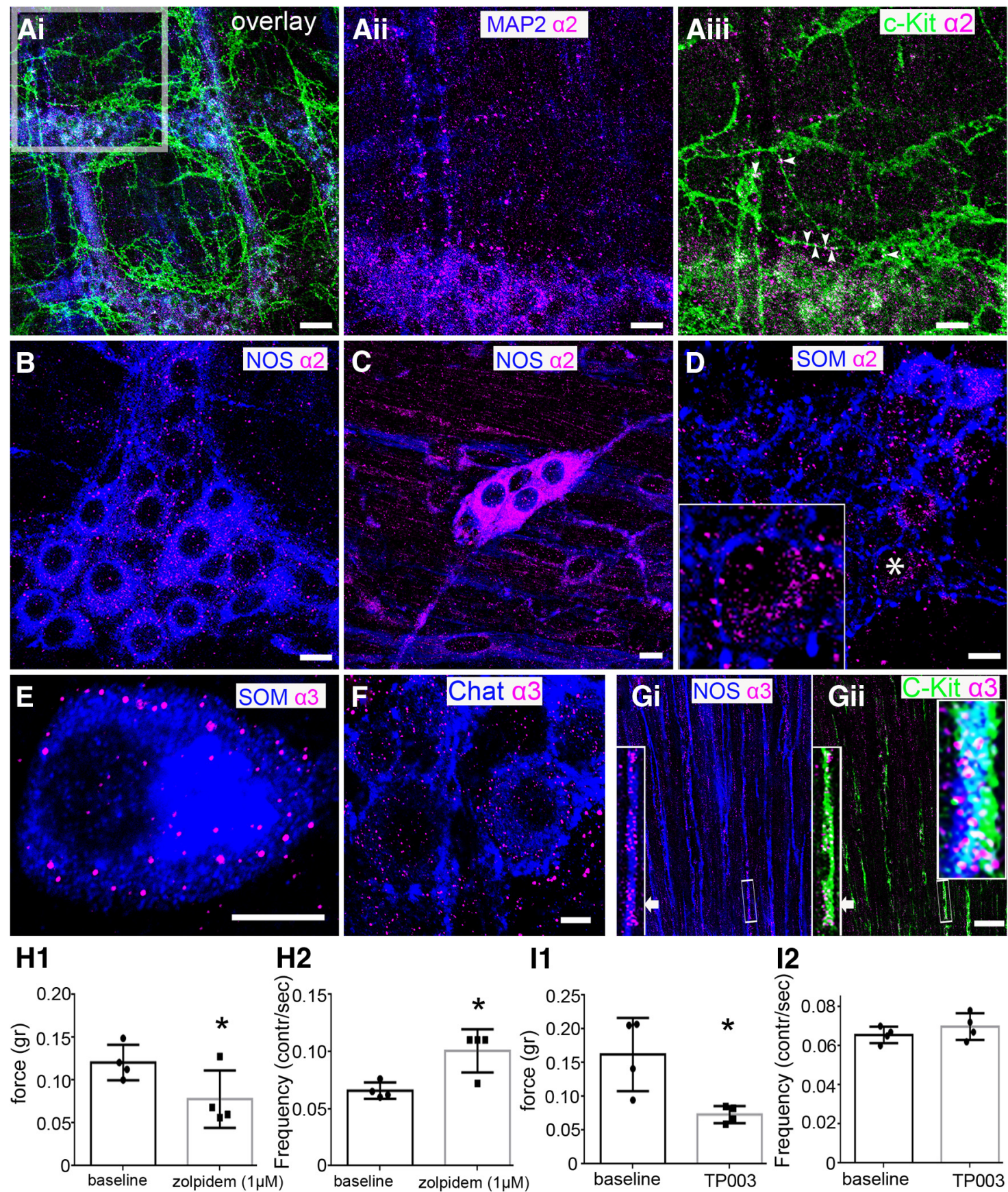

H2

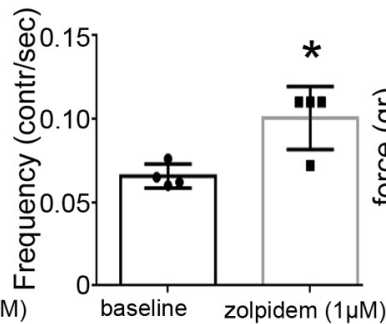

I1

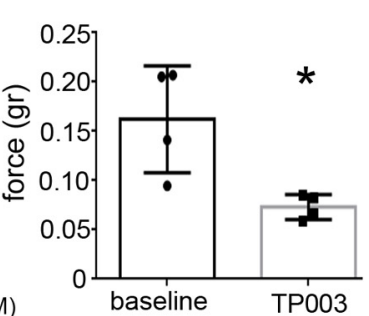

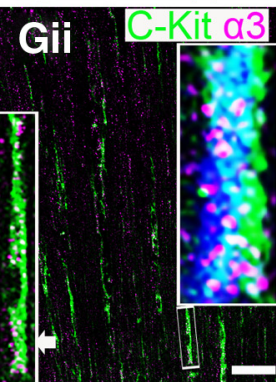

12

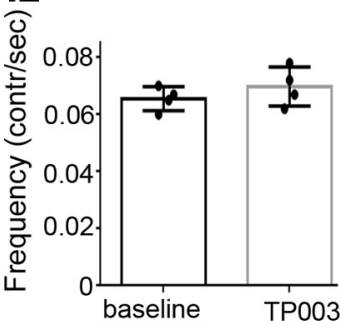

Figure 8. Immunolocalization of the $\mathrm{GABA}_{\mathrm{A}} \mathrm{R} \alpha 2$ and 3 subunits in the ENS of the mouse colon and the pharmacological effect of activating $\alpha 2 / 3-\mathrm{GABA} \mathrm{A}_{\mathrm{A}} \mathrm{R}$ on spontaneous colonic longitudinal smooth muscle contractions. $\boldsymbol{A}$, The association of $\alpha 2$ subunit immunoreactivity with neuronal and non-neuronal cellular profiles in ENS of the mouse colon. Ai, An overlay of immunoreactivity patterns for MAP2 (blue) a marker of neurons, c-Kit (green) a marker of ICC and the $\alpha 2$ subunit (red). Aii, A magnified view of the boxed area in Ai showing the significant association between $\alpha 2$ subunit immunoreactive clusters with MAP2-immunopositive somata and dendrites. Aiii, The corresponding field-of-view shows numerous $\alpha 2$ subunit immunoreactive clusters located on c-Kit-immunopositive profiles (arrowheads). B, Shows $\alpha 2$ subunit immunoreactivity on the somatodendritic surfaces of NOS-immunopositive myenteric plexus neurons. C, Shows the comparative cytoplasmic immunoreactivity pattern for the $\alpha 2$ subunit in NOS-immunopositive submucosal plexus neurons. $\boldsymbol{D}$, Shows $\alpha 2$ subunit immunoreactivity clusters closely apposed to SOMimmunopositive puncta within the myenteric plexus. The insert is a magnified view of the area highlighted by the asterisk. $\boldsymbol{E}$, Shows $\alpha 3$ subunit immunoreactive clusters on the cell body of a SOM-immunopositive myenteric plexus neuron. $\boldsymbol{F}$, Shows $\alpha 3$ subunit immunoreactive clusters closely associated with Chat-immunopositive varicosities. Gi, Shows $\alpha 3$ subunit immunoreactive clusters decorating NOS-immunopositive axon terminals in the muscle layer. Gii, In the corresponding field-of-view, $\alpha 3$-subunit immunoreactive clusters are located in close proximity to c-Kit-immunopositive profiles. The inserts on the left of Gi and Gii are magnified views of the boxed area. Gii, Inset, A magnified merged image of all three channels demonstrating the juxtaposition of $\alpha 3$-subunit immunoreactive clusters between NOS-immunopositive axon terminals and c-Kit-immunopositive profiles which are likely to be ICC. $\boldsymbol{H}$, quantification of the effects of zolpidem $1 \mu \mathrm{M}$ on $(\boldsymbol{H 1})$ the force and $(\boldsymbol{H} \mathbf{2})$ the frequency of spontaneous colonic contractions ( $N=4$ animals). $\boldsymbol{I}$, Quantification of the effects of TP003 $100 \mu \mathrm{m}$ on $(\boldsymbol{I} \mathbf{1})$ the force and $(\boldsymbol{I 2})$ the frequency of spontaneous colonic contractions ( $N=4$ animals). Boxes represent means, the lines represent the SD, and the small squares represent the individual data points; ${ }^{*} p<0.05$ paired Student's $t$ test. Scale bars: $A$ i, $20 \mu \mathrm{m} ;$ Aii, Aiii, $10 \mu \mathrm{m} ; \boldsymbol{B}-\boldsymbol{D}, 10 \mu \mathrm{m} ; \boldsymbol{E}, \boldsymbol{F}, 5 \mu \mathrm{m} ; \boldsymbol{G}, 50 \mu \mathrm{m}$. 
in native $\mathrm{GABA}_{\mathrm{A}} \mathrm{R}$ expression systems (Peden et al., 2008). TP003 at a bath concentration of $100 \mu \mathrm{M}$ significantly decreased the force of spontaneous contractions ( $p=0.024$, paired Student's $t$ test; $N=4$ animals; Fig. 8I1) but had no significant effect on their frequency ( $p=0.294$, paired Student's $t$ test; $N=4$ animals; Fig. 8I2). Collectively, the effects of zolpidem $1 \mu \mathrm{M}$ and TP003 suggest that the activation of $\alpha 2-\mathrm{GABA}_{\mathrm{A}}$ Rs influences the frequency of spontaneous colonic contractions whereas the activation of $\alpha 3-\mathrm{GABA}_{\mathrm{A}} \mathrm{Rs}$ influences the force of spontaneous colonic contractions. We were unable to fully reverse the effects of both zolpidem and TP003 by washout and thus not able to use atropine or L-NAME to evaluate the potential roles of muscarinic cholinergic receptors and nitric oxide pathways in mediating the effects of these drugs.

\section{Expression of the $\alpha 4$ subunit in the mouse colon and its role in the regulation of longitudinal smooth muscle spontaneous contractions}

In contrast to that of the $\gamma 2$ subunit, $\alpha 4$ subunit immunoreactivity was restricted to the neurons and ICC of the myenteric plexus and was not detectable within the submucosal plexus (Fig. 9A). Clusters immunoreactive for the $\alpha 4$ subunit were located on somatodendritic domains of NOS, Chat, 5HT, and CRHimmunopositive neurons (Fig. 9A,B). Thus, within the ENS of the mouse colon, $\mathrm{GABA}_{\mathrm{A}} \mathrm{R}$ subunit expression varies not only according to cell type and subcellular domain but also according to distinct regions of the ENS delineated by the myenteric and submucosal plexuses.

The lack of availability of a selective $\alpha 4-\mathrm{GABA}_{\mathrm{A}} \mathrm{R}$ ligand precluded the unequivocal determination of the contribution of $\alpha 4$ $\mathrm{GABA}_{\mathrm{A}} \mathrm{R}$ activation to colonic contractility. We therefore used the $\mathrm{GABA}_{\mathrm{A}} \mathrm{R}$ agonist THIP, which will be selective for those $\alpha 4$ $\mathrm{GABA}_{\mathrm{A}}$ Rs which are coassembled with $\delta$ subunits (Brown et al., 2002; Stórustovu and Ebert, 2006) with the caveat that $\mathrm{GABA}_{\mathrm{A}} \mathrm{Rs}$ not composed of $\gamma$ or $\delta$ subunits (i.e., $\alpha$ - $\beta$ pentamers) might also be engaged. THIP, at a bath concentration of $10 \mu \mathrm{M}$ significantly increased the force of spontaneous contractions (from $0.11 \pm$ $0.04 \mathrm{~g}$ to $0.19 \pm 0.09 \mathrm{~g}, N=5$ animals; $p=0.0299$, paired Student's $t$ test) but did not significantly alter their frequency (from $0.052 \pm 0.005 \mathrm{~Hz}$ to $0.051 \pm 0.009 \mathrm{~Hz}, N=5$ animals; $p=$ 0.5583 , paired Student's $t$ test).

We then evaluated the effects of THIP in the presence of atropine and L-NAME. While THIP significantly increased the force of colonic contractions on its own ( $p<0.05$, RMA), this effect was abolished in the presence of atropine $(p>0.05, \mathrm{RMA} ; N=5$ animals; Fig. 9C1,C2). In accordance with above, THIP had no significant effect on the frequency of spontaneous contractions either alone $(p>0.05, \mathrm{RMA})$ or in the presence of atropine $(p>$ 0.05, RMA; Fig. 9C3).

In contrast to atropine, the significant $\left(F_{(2,6)} 13.6 ; p=0.0059\right.$. RMA) THIP-induced increase in the force of colonic contractions $(p<0.05, \mathrm{RMA})$ persisted in the presence of L-NAME $(p<0.05$, RMA; $\mathrm{N}=3$ animals; Fig. 9D1,D2). Once again, THIP had no significant effect on the frequency of spontaneous contractions either alone $(p>0.05, \mathrm{RMA})$ or in the presence of L-NAME $(p>0.05$, RMA; Fig. 9D3). Thus, the muscarinic cholinergic system but not the nitric oxide system appears to be involved in mediating the effects of THIP on the force of colonic contractions.

Expression of the $\alpha 5$ subunit in the mouse colon and its role in the regulation of longitudinal smooth muscle spontaneous contractions

In a similar pattern to $\alpha 4$ subunit immunoreactivity, signal for the $\alpha 5$ subunit was restricted to neurons and putative ICC of the myenteric plexus with no $\alpha 5$ subunit immunoreactivity detectable in the submucosal plexus (Fig. 10A). Within the myenteric plexus, immunoreactivity for the $\alpha 5$ subunit was located on the somato-dendritic domains of NOS, CRH and 5HTimmunopositive neurons as well as apposed to Chat immunoreactive varicosities (Fig. 10Ai,B).

L-655,708, an inverse agonist selective for the benzodiazepine site at $\alpha 5-\gamma 2-\mathrm{GABA}_{\mathrm{A}}$ Rs (Quirk et al., 1996), was used to investigate the functional implications of $\alpha 5-\mathrm{GABA}_{\mathrm{A}} \mathrm{Rs}$ activity on the force and frequency of spontaneous contractions of the mouse colon. L-655,708 at a bath concentration of $10 \mu \mathrm{M}$ induced a profound reduction in the basal tone of the tissue (Fig. 10C1, double arrow; from $-0.28 \pm 0.16 \mathrm{~g}$ to $-0.58 \pm 0.18 \mathrm{~g}, N=8$ animals; $p<0.0001$, paired Student's $t$ test). Furthermore, L-655,708 $10 \mu \mathrm{M}$ significantly decreased the force of spontaneous contractions (from $0.13 \pm 0.05 \mathrm{~g}$ to $0.10 \pm 0.02 \mathrm{~g}, N=8$ animals; $p=0.0316$, paired Student's $t$ test). However, L-655,708 did not significantly alter the frequency of contractions (from $0.058 \pm$ $0.010 \mathrm{~Hz}$ to $0.058 \pm 0.011 \mathrm{~Hz}, N=8$ animals; $p=0.8398$, paired Student's $t$ test). Notably, of all the $\mathrm{GABA}_{\mathrm{A}} \mathrm{R}$ ligands tested $\mathrm{L}-655,708$ produced the most robust reduction in the basal tone of the tissue with only alprazolam mimicking such an effect, although to a much lesser degree. This suggests a central role for $\alpha 5-\mathrm{GABA}_{\mathrm{A}} \mathrm{Rs}$ in setting the muscle tone of the mouse colon.

In a separate experiment, we then evaluated the effects of L-655,708 in the presence of atropine and L-NAME. L-655,708 significantly $\left(F_{(5,15)} 3.23 ; p=0.03\right.$, RMA $)$ reduced the basal tone of the colon, both on its own $(p<0.05$, RMA $)$ and in the presence of atropine ( $p<0.05, \mathrm{RMA} ; N=6$ animals). The effect of L-655,708 in significantly $\left(F_{(5,15)} 4.79 ; p=0.0081\right.$, RMA $)$ reducing the force of colonic contractions $(p<0.05$, RMA) persisted in the presence of atropine $(p<0.05$, RMA; Fig. 10C1,C2). In accordance with above, L-655,708 had no significant effect on the frequency of spontaneous contractions either alone $(p>0.05$, RMA) or in the presence of atropine ( $p>0.05$, RMA; Fig. 10C3). The data suggest that the muscarinic cholinergic system is not associated with the effect of L-655,708 on the basal tone or force of colonic contractions.

Although L-655,708 significantly $\left(F_{(5,15)} 5.8 ; p=0.003, \mathrm{RMA}\right)$ reduced the basal tone of the colon on its own $(p<0.05, \mathrm{RMA})$, this effect was abolished in the presence of L-NAME $(p>0.05$, RMA; $N=6$ animals). In contrast to atropine, the significant L-655,708-induced $\left(F_{(5,15)} 4.9 ; p=0.007, \mathrm{RMA}\right)$ decrease in the force of colonic contractions ( $p<0.05$, RMA) was abolished in the presence of L-NAME $(N=6$ animals; $p>0.05$, RMA; Fig. $10 D 1, D 2)$. Once again, L-655,708 had no significant effect on the frequency of spontaneous contractions either alone $(p>0.05$, RMA) or in the presence of L-NAME $(p>0.05$, RMA; $N=6$ animals; Fig. 10D3). Thus, the nitric oxide system is involved in mediating the effects of L-655,708 on both basal tone and the force of colonic contractions.

\section{The effect of $\mathrm{GABA}_{\mathrm{A}} \mathrm{R}$ activation on the stressed induced alterations in colonic longitudinal smooth muscle spontaneous contractions}

Psychosocial stress is a key contributor to the underlying pathology of a number of GI disorders (Konturek et al., 2011), such as IBD and IBS (Taché et al., 2004; Mawdsley and Rampton, 2005; Fichna and Storr, 2012). With a view to elucidating a potential role for $\mathrm{GABA}_{\mathrm{A}} \mathrm{R}$ ligands in influencing stress-induced alterations in colonic contractions, we compared the effects of alprazolam in tissue from control animals and animals exposed to $1 \mathrm{~h}$ of restraint stress. Although alprazolam at a bath concentration 

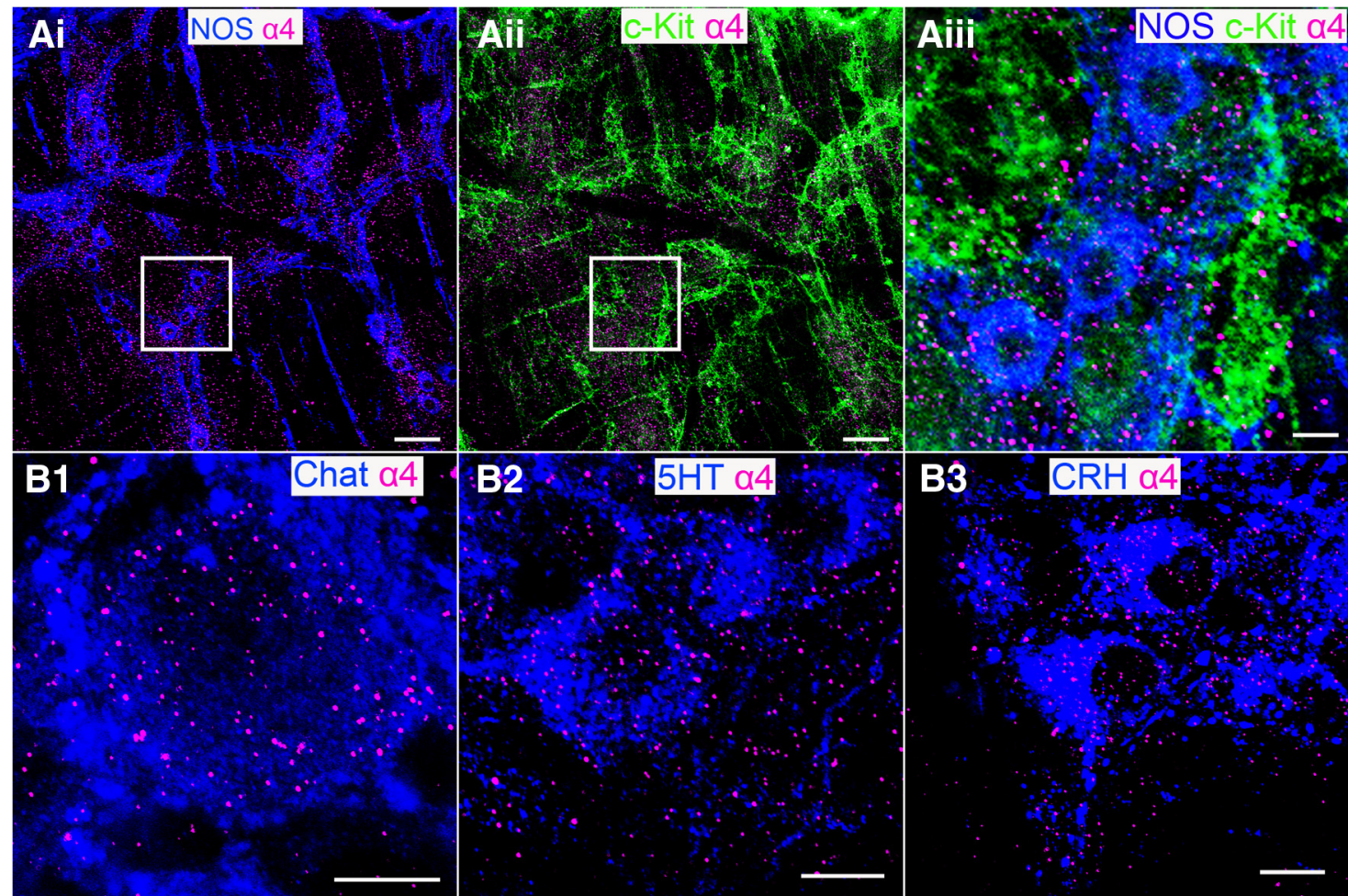

\section{C1}

D1

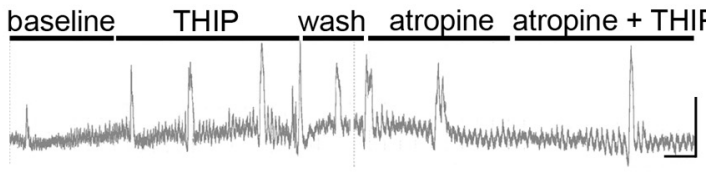

baseline THIP wash L-NAME $\begin{gathered}\text { L-NAME + } \\ \text { THIP }\end{gathered}$

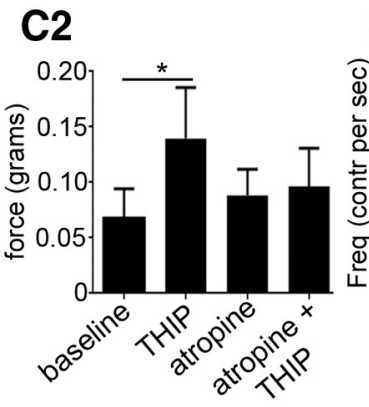

\section{C3}

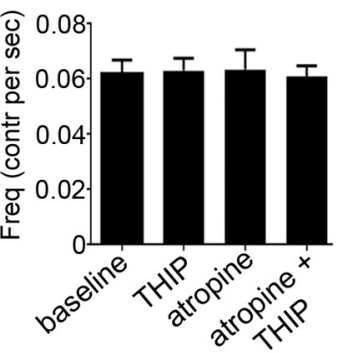

\section{D2}

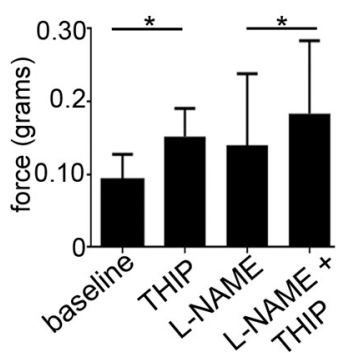

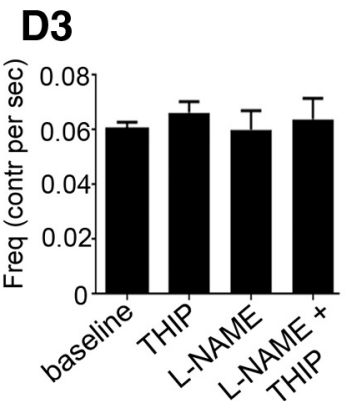

Figure 9. Immunolocalization of the $G A B A_{A} R \alpha 4$ subunit in the ENS of the mouse colon and the pharmacological effect of activating $\alpha 4-G A B A_{A} R s$ on spontaneous colonic longitudinal smooth muscle contractions. Ai, The association of $\alpha 4$ subunit immunoreactive clusters (red) with NOS-immunopositive neurons (blue) of the myenteric plexus. Aii, The association of $\alpha 4$ subunit immunoreactive clusters (red) with c-Kit-immunopositive profiles (green) in the same field-of-view. Aiii, A magnified view of the boxed areas in Ai and Aii demonstrating that $\alpha 4$-subunitimmunoreactive clusters decorate the surfaces of NOS-immunopositive somata and dendrites as well as c-Kit-immunopositive processes. B1, Shows that $\alpha 4$-subunit-immunoreactive clusters are located in the close vicinity of Chat-immunopositive varicosities in the myenteric plexus. Immunoreactivity for the $\alpha 4$-subunit was also detectable on the somatodendritic domains of (B2) $5 \mathrm{HT}$ - and (B3) CRH-immunopositive myenteric plexus neurons. C1, Representative trace demonstrating the effect of THIP $10 \mu \mathrm{m}$ on spontaneous contractions in a piece of isolated mouse colon in the absence and presence of the muscarinic cholinergic receptor antagonist atropine $1 \mu \mathrm{m}$. Quantification of the effects of THIP, before and after the coapplication of atropine on (C2) the force and (C3) the frequency of spontaneous colonic contractions. D1, Representative trace demonstrating the effect of THIP $10 \mu \mathrm{m}$ on spontaneous contractions in a piece of isolated mouse colon in the absence and presence of the nitric oxide synthase inhibitor L-NAME $10 \mu \mathrm{m}$. Quantification of the effects of THIP, before and after the coapplication of L-NAME on (D2) the force and (D3) the frequency of spontaneous colonic contractions. Error bars represent means and the lines represent the SD; $N=5$ animals, ${ }^{*} p<0.05$, RMA with post hoc Tukey's test. Scale bars: Ai, Aii, $50 \mu \mathrm{m} ; A$ Aiii, $10 \mu \mathrm{m} ; \boldsymbol{B}$, $10 \mu \mathrm{m} ; \mathbf{C 1}, \mathbf{D 1}$, vertical $0.25 \mathrm{~g}$, horizontal $2 \mathrm{~min}$.

of $10 \mu \mathrm{M}$ predictably (Fig. 3) reduced the basal tone of tissue from control animals (Fig. 11A1, double arrow), this effect was negligible in tissue from stress animals (Fig. 11A2; control, $-0.17 \pm$ $0.07 \mathrm{~g}$ vs stress, $-0.06 \pm 0.01 \mathrm{~g}, N=8$ animals; $p=0.0021$, unpaired Student's $t$ test). The force of baseline spontaneous contractions were significantly larger in tissue from stress animals compared with control (control, $0.11 \pm 0.01$ vs stress, $0.19 \pm$
0.01, $N=7, p<0.001$, RMA) with large rhythmic contractions superimposed on smaller contractions evident in tissue from stress animals (Fig. 11A2, arrows). Alprazolam significantly decreased $\left(F_{(2.401,14.40)}=44.48, p<0.0001\right.$, RMA $)$ the force of spontaneous colonic contractions in both control $(N=7$ animals; $p<0.001, \mathrm{RMA})$ and stress tissue $(p<0.001, \mathrm{RMA} ; N=7$ animals). Although the same concentration of alprazolam in- 

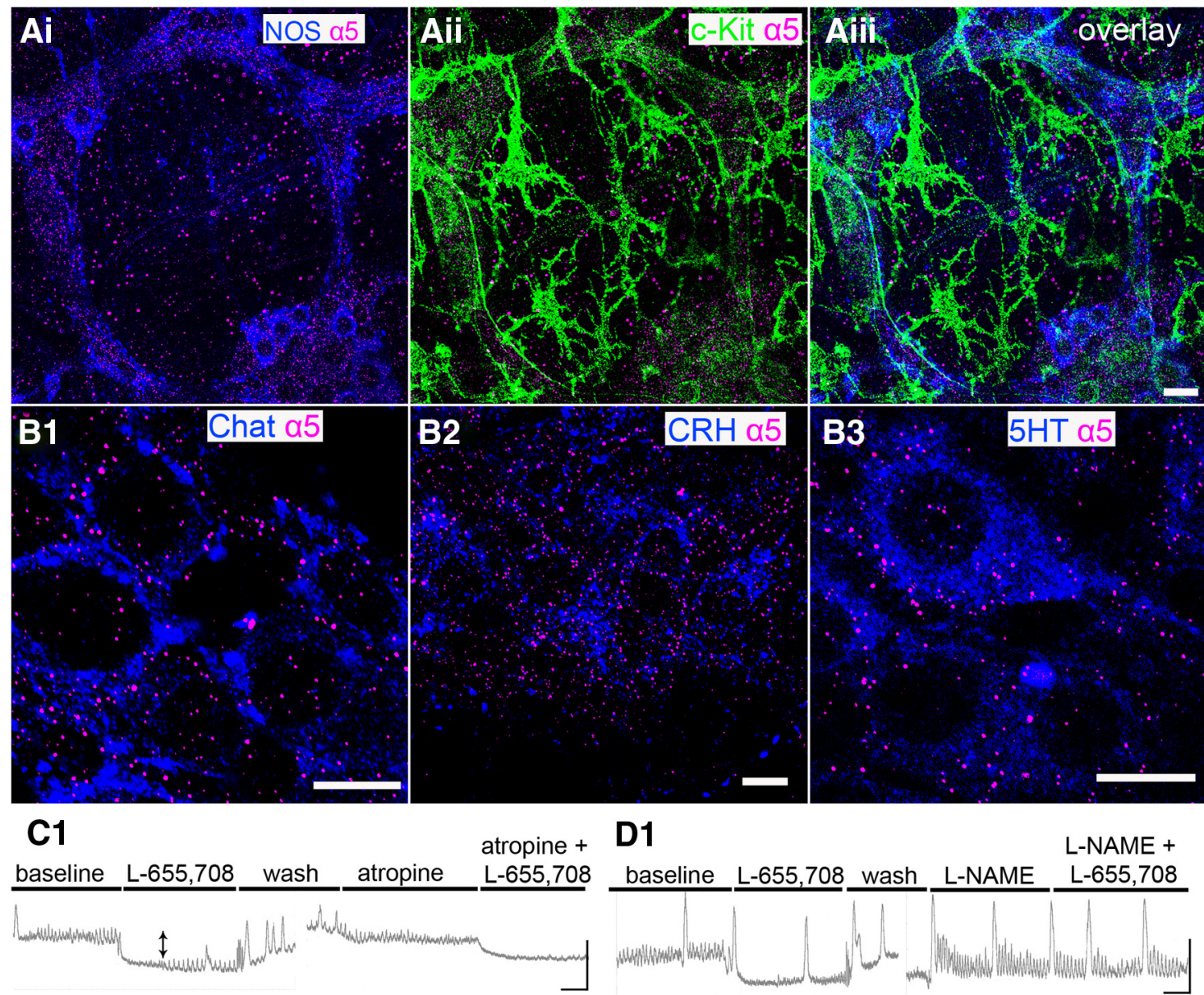

D1

L-NAME +

baseline L-655,708 wash L-NAME L-655,708

\section{C2}

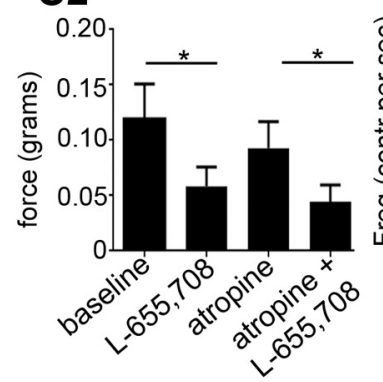

\section{C3}

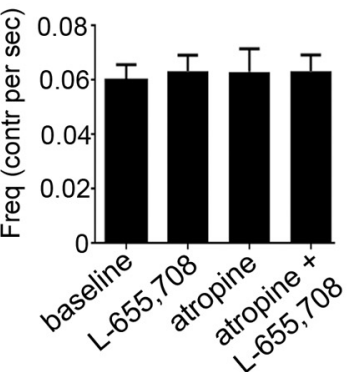

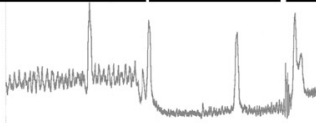

\section{D2}

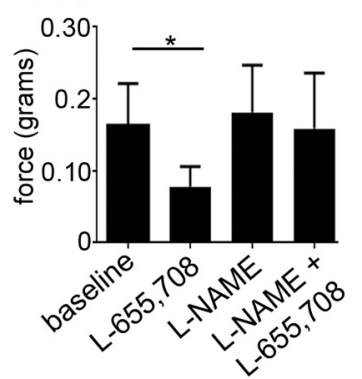

D3

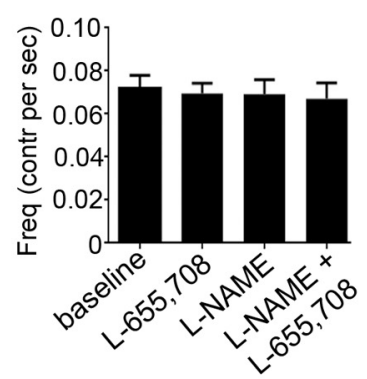

Figure 10. Immunolocalization of the $G A B A_{A} R \alpha 5$ subunit in the ENS of the mouse colon and the pharmacological effect of activating $\alpha 5-G_{A B A} \mathrm{R}_{\mathrm{A}}$ on spontaneous colonic longitudinal smooth muscle contractions. Ai, The association of $\alpha 5$ subunit immunoreactive clusters (red) with NOS-immunopositive neurons (blue) of the myenteric plexus. Note the significant number of $\alpha 5$-subunitimmunoreactive clusters located toward the center of the field-of-view which are not associated with neuronal profiles. Aii, The strong association of $\alpha 5$-subunit-immunoreactive clusters (red) with c-Kit-immunopositive profiles in the same field-of-view. Aiii is an overlay of $\boldsymbol{A}$ i and $\mathbf{A i i}$. B1, Shows that $\alpha 5$-subunit-immunoreactive clusters are located in the close vicinity of Chat-immunopositive varicosities in the myenteric plexus. Immunoreactivity for the $\alpha 5$-subunit was also detectable on the somatodendritic domains of (B2) CRH- and (B3) 5 HT-immunopositive myenteric plexus neurons. C1, Representative trace demonstrating the effect of $\mathrm{L}-655,70810 \mu \mathrm{m}$ on spontaneous contractions in a piece of isolated mouse colon in the absence and presence of the muscarinic cholinergic receptor antagonist atropine $1 \mu \mathrm{m}$. Quantification of the effects of L-655,708, before and after the coapplication of atropine on (C2) the force and (C3) the frequency of spontaneous colonic contractions. D1, Representative trace demonstrating the effect of L-655,708 on spontaneous contractions in a piece of isolated mouse colon in the absence and presence of the nitric oxide synthase inhibitor L-NAME $10 \mu \mathrm{m}$. Quantification of the effects of L-655,708, before and after the coapplication of L-NAME on (D2) the force and (D3) the frequency of spontaneous colonic contractions. Error bars represent means and the lines represent the SD; $N=5$ animals, ${ }^{*} p<0.05$, RMA with posthoc Tukey's test. Scale bars: $\boldsymbol{A}, 20 \mu \mathrm{m} ; \boldsymbol{B}, 10 \mu \mathrm{m} ; \mathbf{C 1}, \mathbf{D 1}$, vertical $0.25 \mathrm{~g}$, horizontal $2 \mathrm{~min}$.

duced a greater percentage reduction in the force of spontaneous colonic contractions in tissue from stress animals compared with control tissue (mean $\pm \mathrm{SD}$ percentage reduction; control, $39.76 \pm 11.4 \%$ vs stress, $53.26 \pm 14.5 \%$ ), the effect did not reach statistical significance ( $p=0.07$, unpaired Student's $t$ test). However, it is notable that alprazolam reduced the force of spontaneous contractions in tissue from stress animals to the levels exhibited at baseline for control tissue (Fig. 11B1). Stress did not significantly alter the frequency of spontaneous contractions $(p>0.05, \mathrm{RMA} ; N=7)$. While alprazolam predictably significantly increased the frequency of spontaneous colonic contractions in tissue from control mice ( $p<0.001, \mathrm{RMA})$, this effect was not evident in tissue from stress animals ( $p>0.05$, RMA). Collectively, these data suggest that drugs targeting $\gamma 2-G_{A B A} R$ have the potential to reverse changes in the force of colonic contractions arising from exposure to stressors. 


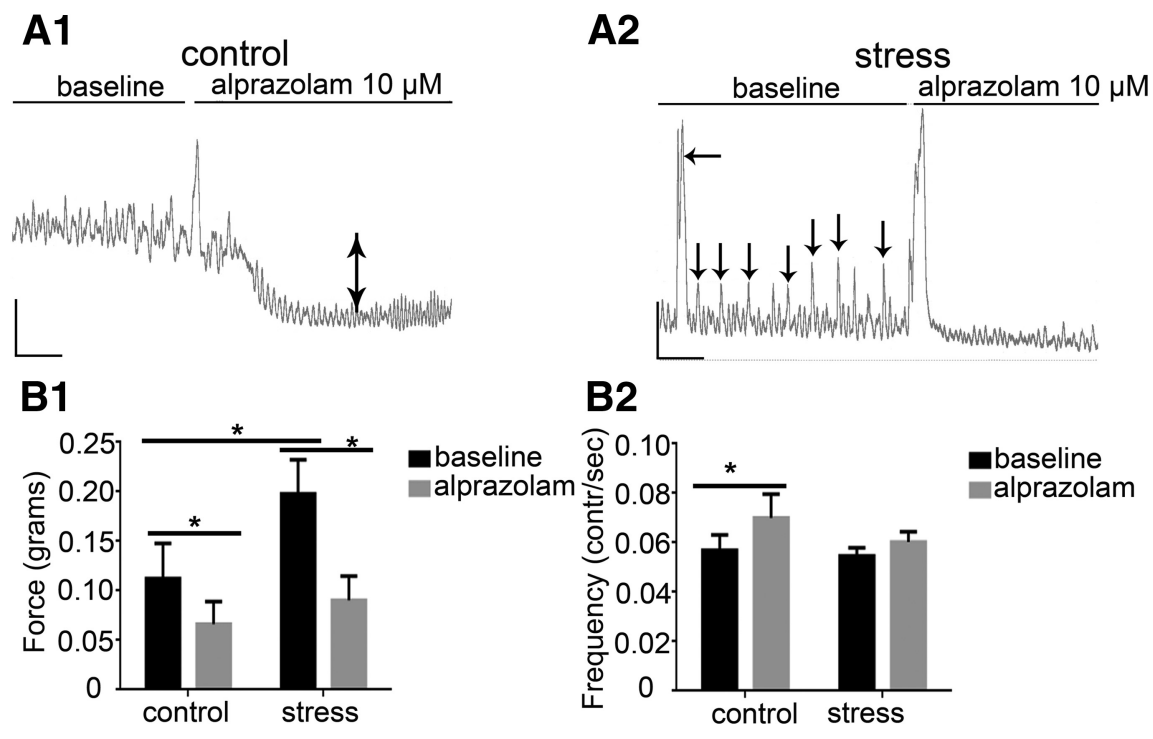

Figure 11. The effects of $\mathrm{GABA}_{A}$ R activation on the stress induced alterations in the force and frequency of colonic spontaneous contractions. $\boldsymbol{A}$, representative traces of the effects of alprazolam $10 \mu \mathrm{m}$ on the contractile responses of colon tissue obtained from (A1) control and (A2) stress animals. Note in $\mathbf{A 2}$, the stress-induced large amplitude rhythmic baseline contractions (arrows) and the absence of the alprazolam-induced reduction in basal tone of the tissue which is evident in the trace from control tissue (A1, double arrow). $\boldsymbol{B}$, Quantification of the comparative effects of alprazolam $10 \mu \mathrm{m}$ on the (B1) force and (B2) frequency of spontaneous contractions in tissue from control and stress animals. Error bars represent means and the lines represent the SD; $N=7$ animals. $p<0.05$, RMA with post hoc Tukey's post hoc test. Scale bars: $\boldsymbol{A}$, vertical $0.3 \mathrm{~g}$, horizontal $2.5 \mathrm{~min}$.

\section{Discussion}

The study shows that immunoreactivity for the $\alpha 1$ and $\gamma 2$ subunits was the most widespread compared with the other subunits investigated, being located on chemically diverse neurons of both myenteric and submucosal plexuses. This preponderance of $\alpha 1-\gamma 2$ subunit immunoreactivity within the ENS mirrors $\mathrm{GABA}_{\mathrm{A}} \mathrm{R}$ expression patterns within the CNS where $\alpha 1-\gamma 2$ $\mathrm{GABA}_{\mathrm{A}} \mathrm{Rs}$ are thought to be the major subtypes (Wisden et al., 1992). Although immunoreactivity for the $\alpha 2$ and 3 subunits was also evident in myenteric and submucosal plexuses, their signals were restricted to smaller subsets of neurochemically defined enteric neurons. In stark contrast, immunoreactivity for the $\alpha 4-5$ subunits was only detectable in myenteric plexus neurons. $\mathrm{GABA}_{\mathrm{A}} \mathrm{R}$ subunit immunoreactivity was also located on nonneuronal cells which are likely to be the ICC that act as pacemakers of the GIT and are involved in the creation of slow wave potentials which leads to the contraction of smooth muscle (Garcia-Lopez et al., 2009). The application of $\mathrm{GABA}_{\mathrm{A}} \mathrm{R}$ subunit preferring ligands induced contrasting effects on the force and frequency of spontaneous contraction of longitudinal smooth muscles of the colon in vitro. Finally, $\alpha-\gamma 2-\mathrm{GABA}_{\mathrm{A}} \mathrm{R}$ activation reversed the stress-induced increase in the force of spontaneous contractions. The study reveals the rich molecular and functional diversity of the $\mathrm{GABA}_{\mathrm{A}} \mathrm{R}$ system within the ENS of the mouse colon and provides a platform for the design of $\mathrm{GABA}_{\mathrm{A}} \mathrm{R}$-based formulations targeted specifically for GI disorders.

\section{Implications of $\mathrm{GABA}_{\mathrm{A}} \mathrm{R}$ subunit expression patterns for colon contractility}

The ENS is capable of providing complete neural control of GI functions independent of input from the CNS (Furness, 2006). Within the mammalian ENS, over thirty functionally distinct types of neurons have been discovered which communicate using $>25$ different neurotransmitters (McConalogue and Furness, 1994; Furness, 2000), including GABA (Jessen et al., 1986). At the organ level, GABA, released predominantly from interneurons and endocrine cells (Krantis, 2000; Furness, 2006), influences various GI functions including motility (Cherubini and North, 1984), secretion (Luzzi et al., 1987), and mucosal function (Hardcastle et al., 1991; MacNaughton et al., 1996). At the single-cell level, applied GABA depolarizes myenteric neurons and thus exerts excitatory postsynaptic effects in the ENS (Cherubini and North, 1984) via $\mathrm{GABA}_{\mathrm{A}} \mathrm{Rs}$ (Cherubini and North, 1985). However, the precise effects of various $\mathrm{GABA}_{\mathrm{A}} \mathrm{R}$ subtypes on the excitability of the functionally and neurochemically diverse ENS neurons remain to be revealed, necessitating a detailed description of their expression patterns in the first instance.

A striking feature of the $\mathrm{GABA}_{\mathrm{A}} \mathrm{R}$ subunit immunoreactivity patterns revealed by this study was the plexus-dependent location of the signal. $\mathrm{GABA}_{\mathrm{A}} \mathrm{R}$ subunit immunoreactivity in myenteric plexus neurons was always located on somatodendritic cell surfaces, regardless of the neurochemical content of the cell. This clustering on postsynaptic domains is the conventional $\mathrm{GABA}_{\mathrm{A}} \mathrm{R}$ subunit expression pattern of the CNS (Fritschy and Mohler, 1995; Nusser et al., 1996; Somogyi et al., 1996) and serves to regulate the neuron which is postsynaptic to the GABA release site (Farrant and Nusser, 2005). In contrast, $\mathrm{GABA}_{\mathrm{A}} \mathrm{R}$ subunit immunoreactivity in submucosal neurons was invariably located cytoplasmically and on axonal varicosities. This suggests a presynaptic locus of expression for $\mathrm{GABA}_{\mathrm{A}} \mathrm{Rs}$ in submucosal neurons which is likely to result in an autoregulatory function that could influence the further release of coexpressed neurotransmitters (Kullmann et al., 2005). It is difficult to speculate what eventual net effect $\mathrm{GABA}_{\mathrm{A}} \mathrm{R}$ activation will have on, for example, myenteric plexus output such as colonic contractility given the fact that nonoverlapping populations of NOS-, somatostatin-, or encephalin-immunopositive GABAergic interneurons innervate both excitatory as well as inhibitory neurons (Krantis, 2000). An added layer of complexity was the association of $G_{A B A} R$ subunit immunoreactivity with non-neuronal cells, which, based on their immunoreactivity, are likely to be the ICCs. ICCs are thought to provide pacemaker activity in terms of intestinal contractions (Garcia-Lopez et al., 2009) suggesting a clear role for $\mathrm{GABA}_{\mathrm{A}} \mathrm{Rs}$ in intestinal motility. Collectively, this cell-typespecific targeting of $\mathrm{GABA}_{\mathrm{A}} \mathrm{Rs}$ to either presynaptic or postsynaptic compartments of submucosal and myenteric plexuses respectively is likely to result in contrasting effects on the excitability of the neurons, the ensuing overall output of the plexuses as a whole, and thus GI function, following the application of $\mathrm{GABA}$ or the ingestion of $\mathrm{GABA}_{\mathrm{A}} \mathrm{R}$ ligands.

To gain a perspective on the potential contributions of various $\mathrm{GABA}_{\mathrm{A}} \mathrm{R}$ subtypes to GI function, we concentrated on the myenteric plexus in light of its readily measurable physiological output, namely colonic spontaneous contractility. Despite the widespread expression of various $\mathrm{GABA}_{\mathrm{A}} \mathrm{R}$ subunits throughout the ENS, it is notable that the $\mathrm{GABA}_{\mathrm{A}} \mathrm{R}$ subunit-preferring ligands had such distinctly opposing effects on longitudinal smooth muscle contractility. Indeed, the pharmacological activation of 
$\alpha 1-\gamma 2-\mathrm{GABA}_{\mathrm{A}}$ Rs and $\alpha 4-\mathrm{GABA}_{\mathrm{A}}$ Rs increased the force of spontaneous contractions, $\alpha 2-\gamma 2-\mathrm{GABA}_{\mathrm{A}} \mathrm{Rs}$ increased their frequency, $\alpha 3-\gamma 2-\mathrm{GABA}_{\mathrm{A}}$ Rs decreased their force and an inverse agonist at $\alpha 5-\gamma 2-\mathrm{GABA}_{\mathrm{A}} \mathrm{Rs}$ decreased their force. This suggests that the engagement of various $\mathrm{GABA}_{\mathrm{A}} \mathrm{R}$ subtypes within the cellular networks of the ENS cooperate to modulate the distinct physiological processes, which underlie coordinated contractility. It would be beneficial to understand which particular $\mathrm{GABA}_{\mathrm{A}} \mathrm{R}$-cellular pathway modulates distinct facets of the contractile process, such as amplitude or frequency. Although the current study suggests the overlap of multiple $\mathrm{GABA}_{\mathrm{A}} \mathrm{R}$ subtypes on neurochemically diverse cell-types, such as those expressing NOS and Chat, these combinatorial pharmacological analyses allow us to draw cautious conclusions on the neurochemical and cellular pathways mediating the $\mathrm{GABA}_{\mathrm{A}} \mathrm{R}$-subtype-dependent effects on the force and frequency of longitudinal muscle colonic contractions. For example, alprazolam, which is likely to preferentially engage $\alpha 2-3-\gamma 2-\mathrm{GABA}_{\mathrm{A}} \mathrm{Rs}$, appeared to induce a decrease in the force of contractions via NO pathways. Furthermore, $\alpha 2 / 3$ $\mathrm{GABA}_{\mathrm{A}} \mathrm{R}$ immunoreactivity was associated with somatostatinimmunopositive neurons, the activation of which via $G_{A B A} R s$ is linked to the release of nitric oxide and vasoactive intestinal peptide from inhibitory motor neurons (Krantis, 2000) and a consequent decrease in intestinal motility, an effect manifested by the pharmacological activation of $\alpha 2 / 3-\gamma 2-G_{A B A}$ Rs. The obvious caveat is that the pharmacology of the $\mathrm{GABA}_{\mathrm{A}} \mathrm{R}$ subunit-preferring ligands has been demonstrated predominantly in either recombinant systems or CNS preparations. Thus, the future characterization of these ligands in GI tissue from $\mathrm{GABA}_{\mathrm{A}} \mathrm{R}$ subunit-specific mutant mouse models will be instrumental in confirming their pharmacological profiles in colon tissue.

\section{$\mathrm{GABA}_{\mathrm{A}} \mathrm{Rs}$ and stress-induced GI disorders}

Dysregulation of the ENS contributes to the pathophysiology of a number of GI disorders including IBS and IBD (Margolis and Gershon, 2009; Ohman and Simrén, 2010). A key component of such disorders, as well as other GI disorders, is psychosocial stress (Mawdsley and Rampton, 2005; Santos et al., 2008). CRH, released primarily from the hypothalamus, is the key mediator of the body's response to stress (Bale and Vale, 2004). However, there are a number of extra-hypothalamic sources of $\mathrm{CRH}$ throughout the body, including the ENS (Liu et al., 2006), presumably functioning to mediate the stress response at a local level (Stengel and Taché, 2010). Importantly, changes in GI CRH and $\mathrm{CRH}$ receptor expression within certain disorders of the GIT have been reported (Taché and Perdue, 2004; Taché et al., 2004; Yuan et al., 2012). The excitability of CRH-containing ENS neurons is likely to determine CRH release within the GIT and is thus integral to GI homeostasis following exposure to stressors. It is notable that robust $\mathrm{GABA}_{\mathrm{A}} \mathrm{R}$ subunit expression was evident on enteric CRH neurons. Because the $\mathrm{GABA}_{\mathrm{A}}$ Rs provide such a central role in regulating neuronal activity, and thus the release of neuronal contents, the modulation of $\mathrm{GABA}_{\mathrm{A}} \mathrm{R}$ activity specifically on enteric $\mathrm{CRH}$-expressing neurons might provide a highly specific strategy for targeting stress-induced GI disorders. Based on the immunoreactivity patterns within this study, drugs targeting $\alpha 1 / 4 / 5-\mathrm{GABA}_{\mathrm{A}} \mathrm{R}$ are likely to influence the activity of at least the $\mathrm{CRH}$-expressing neurons of the ENS. Thus, determining the precise effects of various $\mathrm{GABA}_{\mathrm{A}} \mathrm{R}$ ligands on the excitability of defined sets of ENS neurons is essential for the further judicious design and use of such agents in GI disorders.

Importantly, stressors have been shown to cause a decrease in gastric emptying, an increase in distal colonic motility and accel- eration of intestinal transit (Mayer, 2000). It is thus promising that alprazolam in this study was able to reverse the stressinduced increase in the force of colonic contractions. However, it is currently unclear what the contribution of such stress-induced increase in contractile responses is to stress-related GI pathology, if any. Surprisingly, of the number of therapeutic agents considered for conditions, such as IBS or IBD, $\mathrm{GABA}_{\mathrm{A}} \mathrm{R}$ ligands are largely overlooked (Hammerle and Surawicz, 2008; Saad and Chey, 2008), although recent evidence is promising (Salari and Abdollahi, 2011). The rich field of $\mathrm{GABA}_{\mathrm{A}} \mathrm{R}$ pharmacology ( $\mathrm{Ru}$ dolph and Möhler, 2006; Rudolph and Knoflach, 2011) is littered with agents that showed promising pharmacological profiles but have translated poorly to the clinic due to either unacceptable central side effects or poor CNS penetration. The current study provides the scientific rationale for the re-evaluation of such agents with a view to reformulating them specifically for delivery to the GIT. In conclusion, the study provides a detailed description of the location of diverse $\mathrm{GABA}_{\mathrm{A}} \mathrm{R}$ subunits expressed within the complex network of neurons composing the ENS of the mouse colon. The fledgling functional analyses provides a firm mandate for further exploring the individual roles of specific $\mathrm{GABA}_{\mathrm{A}} \mathrm{R}$ subtypes in GI functional and associated disorders.

\section{References}

Akinci MK, Schofield PR (1999) Widespread expression of GABA(A) receptor subunits in peripheral tissues. Neurosci Res 35:145-153. CrossRef Medline

Armstrong CL, Chung SH, Armstrong JN, Hochgeschwender U, Jeong YG, Hawkes R (2009) A novel somatostatin-immunoreactive mossy fiber pathway associated with HSP25-immunoreactive purkinje cell stripes in the mouse cerebellum. J Comp Neurol 517:524-538. CrossRef Medline

Bale TL, Vale WW (2004) CRF and CRF receptors: role in stress responsivity and other behaviors. Annu Rev Pharmacol Toxicol 44:525-557. CrossRef Medline

Bayer S, Crenner F, Aunis D, Angel F (2002) Effects of GABA on circular smooth muscle spontaneous activities of rat distal colon. Life Sci 71:911925. CrossRef Medline

Bayer S, Jellali A, Crenner F, Aunis D, Angel F (2003) Functional evidence for a role of GABA receptors in modulating nerve activities of circular smooth muscle from rat colon in vitro. Life Sci 72:1481-1493. CrossRef Medline

Belelli D, Harrison NL, Maguire J, Macdonald RL, Walker MC, Cope DW (2009) Extrasynaptic GABAA receptors: form, pharmacology, and function. J Neurosci 29:12757-12763. CrossRef Medline

Brown N, Kerby J, Bonnert TP, Whiting PJ, Wafford KA (2002) Pharmacological characterization of a novel cell line expressing human alpha(4)beta(3)delta GABA(A) receptors. Br J Pharmacol 136:965-974. CrossRef Medline

Buynitsky T, Mostofsky DI (2009) Restraint stress in biobehavioral research: recent developments. Neurosci Biobehav Rev 33:1089-1098. CrossRef Medline

Cauli B, Tong XK, Rancillac A, Serluca N, Lambolez B, Rossier J, Hamel E (2004) Cortical GABA interneurons in neurovascular coupling: relays for subcortical vasoactive pathways. J Neurosci 24:8940-8949. CrossRef Medline

Cherubini E, North RA (1984) Actions of gamma-aminobutyric acid on neurones of guinea-pig myenteric plexus. Br J Pharmacol 82:93-100. CrossRef Medline

Cherubini E, North RA (1985) Benzodiazepines both enhance gammaaminobutyrate responses and decrease calcium action potentials in guinea-pig myenteric neurones. Neuroscience 14:309-315. CrossRef Medline

Chih B, Engelman H, Scheiffele P (2005) Control of excitatory and inhibitory synapse formation by neuroligins. Science 307:1324-1328. CrossRef Medline

Collin M, Håkansson-Ovesjö ML, Misane I, Ogren SO, Meister B (2000) Decreased 5-HT transporter mRNA in neurons of the dorsal raphe nucleus and behavioral depression in the obese leptin-deficient ob/ob mouse. Brain Res Mol Brain Res 81:51-61. CrossRef Medline 
Corteen NL, Cole TM, Sarna A, Sieghart W, Swinny JD (2011) Localization of GABA-A receptor alpha subunits on neurochemically distinct cell types in the rat locus coeruleus. Eur J Neurosci 34:250-262. CrossRef Medline

Crestani F, Martin JR, Möhler H, Rudolph U (2000) Mechanism of action of the hypnotic zolpidem in vivo. Br J Pharmacol 131:1251-1254. CrossRef Medline

De Jaco A, Comoletti D, Kovarik Z, Gaietta G, Radic Z, Lockridge O, Ellisman MH, Taylor P (2006) A mutation linked with autism reveals a common mechanism of endoplasmic reticulum retention for the alpha,betahydrolase fold protein family. J Biol Chem 281:9667-9676. CrossRef Medline

Dias R, Sheppard WF, Fradley RL, Garrett EM, Stanley JL, Tye SJ, Goodacre S, Lincoln RJ, Cook SM, Conley R, Hallett D, Humphries AC, Thompson SA, Wafford KA, Street LJ, Castro JL, Whiting PJ, Rosahl TW, Atack JR, McKernan RM, Dawson GR, Reynolds DS (2005) Evidence for a significant role of alpha 3 -containing GABAA receptors in mediating the anxiolytic effects of benzodiazepines. J Neurosci 25:10682-10688. CrossRef Medline

Dimitrov E, Usdin TB (2010) Tuberoinfundibular peptide of 39 residues modulates the mouse hypothalamic-pituitary-adrenal axis via paraventricular glutamatergic neurons. J Comp Neurol 518:4375-4394. CrossRef Medline

Di Nardo G, Blandizzi C, Volta U, Colucci R, Stanghellini V, Barbara G, Del Tacca M, Tonini M, Corinaldesi R, De Giorgio R (2008) Review article: molecular, pathological and therapeutic features of human enteric neuropathies. Aliment Pharmacol Ther 28:25-42. CrossRef Medline

Eyre MD, Renzi M, Farrant M, Nusser Z (2012) Setting the time course of inhibitory synaptic currents by mixing multiple GABA(A) receptor alpha subunit isoforms. J Neurosci 32:5853-5867. CrossRef Medline

Farrant M, Nusser Z (2005) Variations on an inhibitory theme: phasic and tonic activation of GABA(A) receptors. Nat Rev Neurosci 6:215-229. CrossRef Medline

Fichna J, Storr MA (2012) Brain-gut interactions in IBS. Front Pharmacol 3:127. CrossRef Medline

Fish KN, Hoftman GD, Sheikh W, Kitchens M, Lewis DA (2013) Parvalbumin-containing chandelier and basket cell boutons have distinctive modes of maturation in monkey prefrontal cortex. J Neurosci 33: 8352-8358. CrossRef Medline

Fritschy JM, Mohler H (1995) GABAA-receptor heterogeneity in the adult rat brain: differential regional and cellular distribution of seven major subunits. J Comp Neurol 359:154-194. CrossRef Medline

Furness JB (2000) Types of neurons in the enteric nervous system. J Auton Nerv Syst 81:87-96. CrossRef Medline

Furness JB (2006) The enteric nervous system. Malden, Mass: Blackwell.

Furness JB (2008) The enteric nervous system: normal functions and enteric neuropathies. Neurogastroenterol Motil 20:32-38. CrossRef Medline

Garcia-Lopez P, Garcia-Marin V, Martínez-Murillo R, Freire M (2009) Updating old ideas and recent advances regarding the interstitial cells of Cajal. Brain Res Rev 61:154-169. CrossRef Medline

Geis C, Weishaupt A, Hallermann S, Grünewald B, Wessig C, Wultsch T, Reif A, Byts N, Beck M, Jablonka S, Boettger MK, Üçeyler N, Fouquet W, Gerlach M, Meinck HM, Sirén AL, Sigrist SJ, Toyka KV, Heckmann M, Sommer C (2010) Stiff person syndrome-associated autoantibodies to amphiphysin mediate reduced GABAergic inhibition. Brain 133:31663180. CrossRef Medline

Glassmeier G, Herzig KH, Höpfner MH, Lemmer K, Jansen A, Scherubl H (1998) Expression of functional GABAA receptors in cholecystokininsecreting gut neuroendocrine murine STC-1 cells. J Physiol 510:805-814. CrossRef Medline

Goyal RK, Hirano I (1996) The enteric nervous system. N Engl J Med 334: 1106-1115. CrossRef Medline

Gustincich S, Feigenspan A, Sieghart W, Raviola E (1999) Composition of the GABAA receptors of retinal dopaminergic neurons. J Neurosci 19: 7812-7822. Medline

Hammerle CW, Surawicz CM (2008) Updates on treatment of irritable bowel syndrome. World J Gastroenterol 14:2639-2649. CrossRef Medline

Hardcastle J, Hardcastle PT, Mathias WJ (1991) The influence of the gamma-amino butyric acid (GABA) antagonist bicuculline on transport processes in rat small intestine. J Pharm Pharmacol 43:128-130. CrossRef Medline

Häring M, Marsicano G, Lutz B, Monory K (2007) Identification of the cannabinoid receptor type 1 in serotonergic cells of raphe nuclei in mice. Neuroscience 146:1212-1219. CrossRef Medline

Härtig W, Stieler J, Boerema AS, Wolf J, Schmidt U, Weissfuss J, Bullmann T, Strijkstra AM, Arendt T (2007) Hibernation model of tau phosphorylation in hamsters: selective vulnerability of cholinergic basal forebrain neurons -implications for Alzheimer's disease. Eur J Neurosci 25:69-80. CrossRef Medline

Hebeiss K, Kilbinger H (1999) Cholinergic and GABAergic regulation of nitric oxide synthesis in the guinea pig ileum. Am J Physiol 276:G862G866. Medline

Heinze L, Harvey RJ, Haverkamp S, Wässle H (2007) Diversity of glycine receptors in the mouse retina: localization of the alpha4 subunit. J Comp Neurol 500:693-707. CrossRef Medline

Hermanstyne TO, Kihira Y, Misono K, Deitchler A, Yanagawa Y, Misonou H (2010) Immunolocalization of the voltage-gated potassium channel Kv2.2 in GABAergic neurons in the basal forebrain of rats and mice. J Comp Neurol 518:4298-4310. CrossRef Medline

Hirst GD, Ward SM (2003) Interstitial cells: involvement in rhythmicity and neural control of gut smooth muscle. J Physiol 550:337-346. CrossRef Medline

Hörtnagl H, Tasan RO, Wieselthaler A, Kirchmair E, Sieghart W, Sperk G (2013) Patterns of mRNA and protein expression for 12 GABAA receptor subunits in the mouse brain. Neuroscience 236:345-372. CrossRef Medline

Huizinga JD, Zarate N, Farrugia G (2009) Physiology, injury, and recovery of interstitial cells of Cajal: basic and clinical science. Gastroenterology 137:1548-1556. CrossRef Medline

Iino S, Horiguchi K (2006) Interstitial cells of cajal are involved in neurotransmission in the gastrointestinal tract. Acta histochemica et cytochemica 39:145-153. CrossRef Medline

Jessen KR, Hills JM, Saffrey MJ (1986) Immunohistochemical demonstration of GABAergic neurons in the enteric nervous system. J Neurosci 6:1628-1634. Medline

Konturek PC, Brzozowski T, Konturek SJ (2011) Stress and the gut: pathophysiology, clinical consequences, diagnostic approach and treatment options. J Physiol Pharmacol 62:591-599. Medline

Krantis A (2000) GABA in the mammalian enteric nervous system. News Physiol Sci 15:284-290. Medline

Krantis A, Shabnavard L, Nichols K, de Blas AL, Staines W (1995) Localization of GABAA receptor immunoreactivity in NO synthase positive myenteric neurones. J Auton Nerv Syst 53:157-165. CrossRef Medline

Kullmann DM, Ruiz A, Rusakov DM, Scott R, Semyanov A, Walker MC (2005) Presynaptic, extrasynaptic and axonal GABAA receptors in the CNS: where and why? Prog Biophys Mol Biol 87:33-46. CrossRef Medline

Langer SZ, Arbilla S, Benavides J, Scatton B (1990) Zolpidem and alpidem: two imidazopyridines with selectivity for omega 1- and omega 3-receptor subtypes. Adv Biochem Psychopharmacol 46:61-72. Medline

Larauche M, Kiank C, Tache Y (2009) Corticotropin releasing factor signaling in colon and ileum: regulation by stress and pathophysiological implications. J Physiol Pharmacol 60:33-46. Medline

Liu S, Gao N, Hu HZ, Wang X, Wang GD, Fang X, Gao X, Xia Y, Wood JD (2006) Distribution and chemical coding of corticotropin-releasing factor-immunoreactive neurons in the guinea pig enteric nervous system. J Comp Neurol 494:63-74. CrossRef Medline

Liu S, Qu MH, Ren W, Hu HZ, Gao N, Wang GD, Wang XY, Fei G, Zuo F, Xia Y, Wood JD (2008) Differential expression of canonical (classical) transient receptor potential channels in guinea pig enteric nervous system. J Comp Neurol 511:847-862. CrossRef Medline

Luzzi S, Franchi-Micheli S, Ciuffi M, Rosi E, Zilletti L (1987) Effect of various GABA-receptor agonists and antagonists on anaphylactic histamine release in the guinea-pig ileum. Agents Actions 20:181-184. CrossRef Medline

MacNaughton WK, Pineau BC, Krantis A (1996) Gamma-aminobutyric acid stimulates electrolyte transport in the guinea pig ileum in vitro. Gastroenterology 110:498-507. CrossRef Medline

Maeda H, Yamagata A, Nishikawa S, Yoshinaga K, Kobayashi S, Nishi K, Nishikawa S (1992) Requirement of c-kit for development of intestinal pacemaker system. Development 116:369-375. Medline

Margolis KG, Gershon MD (2009) Neuropeptides and inflammatory bowel disease. Curr Opin Gastroenterol 25:503-511. CrossRef Medline

Mawdsley JE, Rampton DS (2005) Psychological stress in IBD: new insights 
into pathogenic and therapeutic implications. Gut 54:1481-1491. CrossRef Medline

Mayer EA (2000) The neurobiology of stress and gastrointestinal disease. Gut 47:861-869. CrossRef Medline

McConalogue K, Furness JB (1994) Gastrointestinal neurotransmitters. Baillieres Clin Endocrinol Metab 8:51-76. CrossRef Medline

Nusser Z, Sieghart W, Benke D, Fritschy JM, Somogyi P (1996) Differential synaptic localization of two major gamma-aminobutyric acid type A receptor alpha subunits on hippocampal pyramidal cells. Proc Natl Acad Sci U S A 93:11939-11944. CrossRef Medline

Ohman L, Simrén M (2010) Pathogenesis of IBS: role of inflammation, immunity and neuroimmune interactions. Nat Rev Gastroenterol Hepatol 7:163-173. CrossRef Medline

Olsen RW, Sieghart W (2009) GABA A receptors: subtypes provide diversity of function and pharmacology. Neuropharmacology 56:141-148. CrossRef Medline

Peden DR, Petitjean CM, Herd MB, Durakoglugil MS, Rosahl TW, Wafford K, Homanics GE, Belelli D, Fritschy JM, Lambert JJ (2008) Developmental maturation of synaptic and extrasynaptic GABAA receptors in mouse thalamic ventrobasal neurones. J Physiol 586:965-987. CrossRef Medline

Pirker S, Schwarzer C, Wieselthaler A, Sieghart W, Sperk G (2000) GABA(A) receptors: immunocytochemical distribution of 13 subunits in the adult rat brain. Neuroscience 101:815-850. CrossRef Medline

Poulter MO, Singhal R, Brown LA, Krantis A (1999) GABA(A) receptor subunit messenger RNA expression in the enteric nervous system of the rat: implications for functional diversity of enteric GABA(A) receptors. Neuroscience 93:1159-1165. CrossRef Medline

Quirk K, Blurton P, Fletcher S, Leeson P, Tang F, Mellilo D, Ragan CI, McKernan RM (1996) [3H] L-655,708, a novel ligand selective for the benzodiazepine site of GABAA receptors which contain the alpha 5 subunit. Neuropharmacology 35:1331-1335. CrossRef Medline

Roberts DJ, Hasler WL, Owyang C (1993) GABA mediation of the dual effects of somatostatin on guinea pig ileal myenteric cholinergic transmission. Am J Physiol 264:G953-G960. Medline

Rudolph U, Knoflach F (2011) Beyond classical benzodiazepines: novel therapeutic potential of GABAA receptor subtypes. Nat Rev Drug Discov 10:685-697. CrossRef Medline

Rudolph U, Möhler H (2006) GABA-based therapeutic approaches: GABAA receptor subtype functions. Curr Opin Pharmacol 6:18-23. CrossRef Medline

Saad RJ, Chey WD (2008) Recent developments in the therapy of irritable bowel syndrome. Expert Opin Investig Drugs 17:117-130. CrossRef Medline

Salari P, Abdollahi M (2011) Systematic review of modulators of benzodiazepine receptors in irritable bowel syndrome: is there hope? World J Gastroenterol 17:4251-4257. CrossRef Medline

Sanders KM, Ward SM (2006) Interstitial cells of Cajal: a new perspective on smooth muscle function. J Physiol 576:721-726. CrossRef Medline

Sanders KM, Koh SD, Ordög T, Ward SM (2004) Ionic conductances involved in generation and propagation of electrical slow waves in phasic gastrointestinal muscles. Neurogastroenterol Motil 16:100-105. CrossRef Medline

Santos J, Alonso C, Vicario M, Ramos L, Lobo B, Malagelada JR (2008) Neuropharmacology of stress-induced mucosal inflammation: implications for inflammatory bowel disease and irritable bowel syndrome. Curr Mol Med 8:258-273. CrossRef Medline

Sato D, Lai ZF, Tokutomi N, Tokutomi Y, Maeda H, Nishikawa S, Nishikawa S, Ogawa M, Nishi K (1996) Impairment of Kit-dependent development of interstitial cells alters contractile responses of murine intestinal tract. Am J Physiol 271:G762-G771. Medline

Schock SC, Jolin-Dahel KS, Schock PC, Theiss S, Arbuthnott GW, GarciaMunoz M, Staines WA (2012) Development of dissociated cryopreserved rat cortical neurons in vitro. J Neurosci Methods 205:324-333. CrossRef Medline

Shah V, Lyford G, Gores G, Farrugia G (2004) Nitric oxide in gastrointestinal health and disease. Gastroenterology 126:903-913. CrossRef Medline

Sieghart W (2006) Structure, pharmacology, and function of GABAA receptor subtypes. Adv Pharmacol 54:231-263. CrossRef Medline

Smith TK, Robertson WJ (1998) Synchronous movements of the longitudi- nal and circular muscle during peristalsis in the isolated guinea-pig distal colon. J Physiol 506:563-577. CrossRef Medline

Somogyi P, Fritschy JM, Benke D, Roberts JD, Sieghart W (1996) The gamma 2 subunit of the GABAA receptor is concentrated in synaptic junctions containing the alpha 1 and beta $2 / 3$ subunits in hippocampus, cerebellum and globus pallidus. Neuropharmacology 35:1425-1444. CrossRef Medline

Stanić D, Kuteeva E, Nylander I, Hökfelt T (2010) Characterization of CGRP protein expression in "satellite-like" cells and dendritic arbours of the mouse olfactory bulb. J Comp Neurol 518:770-784. CrossRef Medline

Stengel A, Taché Y (2010) Corticotropin-releasing factor signaling and visceral response to stress. Exp Biol Med (Maywood) 235:1168-1178. CrossRef Medline

Stórustovu SI, Ebert B (2006) Pharmacological characterization of agonists at delta-containing GABAA receptors: functional selectivity for extrasynaptic receptors is dependent on the absence of gamma2. J Pharmacol Exp Ther 316:1351-1359. CrossRef Medline

Taché Y, Perdue MH (2004) Role of peripheral CRF signalling pathways in stress-related alterations of gut motility and mucosal function. Neurogastroenterol Motil 16:137-142. CrossRef Medline

Taché Y, Martinez V, Wang L, Million M (2004) CRF1 receptor signaling pathways are involved in stress-related alterations of colonic function and viscerosensitivity: implications for irritable bowel syndrome. Br J Pharmacol 141:1321-1330. CrossRef Medline

Tanaka YH, Tanaka YR, Fujiyama F, Furuta T, Yanagawa Y, Kaneko T (2011) Local connections of layer 5 GABAergic interneurons to corticospinal neurons. Front Neural Circuits 5:12. CrossRef Medline

Tan S, Rudd JA, Yew DT (2011) Gene expression changes in GABAA receptors and cognition following chronic ketamine administration in mice. PLoS One 6:e21328. CrossRef Medline

Tonini M, Onori L, Rizzi CA, Perucca E, Manzo L, Crema A (1987) Involvement of substance $\mathrm{P}$ in the excitatory action of GABAA agonists on cholinergic neurons in the guinea-pig ileum. Naunyn Schmiedebergs Arch Pharmacol 335:629-635. CrossRef Medline

Tonini M, De Petris G, Onori L, Manzo L, Rizzi CA, Crema A (1989a) The role of GABAA receptor function in peristaltic activity of the guinea-pig ileum: a comparative study with bicuculline, SR 95531 and picrotoxinin. Br J Pharmacol 97:556-562. CrossRef Medline

Tonini M, Crema A, Frigo GM, Rizzi CA, Manzo L, Candura SM, Onori L (1989b) An in vitro study of the relationship between GABA receptor function and propulsive motility in the distal colon of the rabbit. Br J Pharmacol 98:1109-1118. CrossRef Medline

Torihashi S, Ward SM, Nishikawa S, Nishi K, Kobayashi S, Sanders KM (1995) c-kit-Dependent development of interstitial cells and electrical activity in the murine gastrointestinal tract. Cell Tissue Res 280:97-111. CrossRef Medline

Varoqueaux F, Jamain S, Brose N (2004) Neuroligin 2 is exclusively localized to inhibitory synapses. Eur J Cell Biol 83:449-456. CrossRef Medline

Ward SM, Sanders KM, Hirst GD (2004) Role of interstitial cells of Cajal in neural control of gastrointestinal smooth muscles. Neurogastroenterol Motil 16:112-117. CrossRef Medline

Wisden W, Laurie DJ, Monyer H, Seeburg PH (1992) The distribution of 13 GABAA receptor subunit mRNAs in the rat brain: I. Telencephalon, diencephalon, mesencephalon. J Neurosci 12:1040-1062. Medline

Wisłowska-Stanek A, Lehner M, Skórzewska A, Krzạścik P, Maciejak P, Szyndler J, Ziemba A, Płaźnik A (2013) Changes in the brain expression of alpha-2 subunits of the GABA-A receptor after chronic restraint stress in low- and high-anxiety rats. Behav Brain Res 253:337-345. CrossRef Medline

Yuan PQ, Wu SV, Elliott J, Anton PA, Chatzaki E, Million M, TachéY (2012) Expression of corticotropin releasing factor receptor type 1 (CRF1) in the human gastrointestinal tract and upregulation in the colonic mucosa in patients with ulcerative colitis. Peptides 38:62-69. CrossRef Medline

Zeiter DK, Li X, Broussard DL (1996) Identification of the GABAA receptor alpha-subunit mRNA in rat intestine. Brain Res Mol Brain Res 39:241244. CrossRef Medline

Zheng PY, Feng BS, Oluwole C, Struiksma S, Chen X, Li P, Tang SG, Yang PC (2009) Psychological stress induces eosinophils to produce corticotrophin releasing hormone in the intestine. Gut 58:1473-1479. CrossRef Medline 